\title{
GUIDELINE
}

\section{Adult antiretroviral therapy guidelines 2014}

\section{By the Southern African HIV Clinicians Society}

\author{
G Meintjes (chairperson)
}

J Black, F Conradie, V Cox, S Dlamini, J Fabian, G Maartens, T Manzini, M Mathe, C Menezes, M Moorhouse, Y Moosa,

J Nash, C Orrell, Y Pakade, F Venter, D Wilson (expert panel members)

Correspondence: Southern African HIV Clinicians Society (sahivsoc@sahivsoc.org)

Disclaimer: Specific recommendations provided here are intended only as a guide to clinical management, based on expert consensus and best current evidence. Treatment decisions for patients should be made by their responsible clinicians, with due consideration for individual circumstances. The most current version of this document should always be consulted.

These guidelines are intended as an update to those published in the Southern African Journal of HIV Medicine in 2012. Since the release of the previous guidelines, the scale-up of antiretroviral therapy (ART) in southern Africa has continued. Cohort studies from the region show excellent clinical outcomes; however, ART is still being initiated late (in advanced disease) in some patients, resulting in relatively high early mortality rates. New data on antiretroviral drugs have become available. Although currently few, there are patients in the region who are failing protease-inhibitor-based second-line regimens. To address this, guidelines on third-line therapy have been expanded.

S Afr J HIV Med 2014;15(4):121-143. DOI:10.7196/SAJHIVMED.1130

口ir.:回

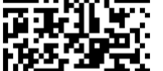

1. Key principles

While many antiretroviral therapy (ART) guidelines are available internationally, the current guidelines have been written to add-

ress issues relevant to southern Africa. The following general principles underpinned the writing process:

- South Africa (SA) is a middle-income country, whereas certain other countries in the region are low-income countries; therefore, affordability was taken into account.

- Only treatment and diagnostic options available in southern Africa were included.

- We recognised the need to bridge the gap in treatment recommendations between public and private sector programmes, considering that many patients transition between the two sectors for treatment.

- While it is acknowledged that certain recommendations are aspirational for poorly resourced settings, the unavailability of diagnostic/monitoring tests should not pose a barrier to providing ART to those in need.

- There has been a shift to view ART as a means of HIV prevention. The clinical trial evidence base for this exists for serodiscordant couples; recommendations in this regard are included in these guidelines and additional data from randomised community studies are awaited.

\section{Goals of ART}

The primary goals of ART are to:

- improve quality of life

- reduce HIV-related morbidity and mortality
- provide maximal and durable suppression of viral load (VL) - restore and/or preserve immune function.

These goals are achieved by suppressing viral replication completely for as long as possible, using well-tolerated and sustainable treatment taken with good adherence. With prolonged viral suppression, the $\mathrm{CD} 4^{+}$lymphocyte count usually increases, which is accompanied by a restoration of pathogen-specific immune function. For most patients, this results in a dramatic reduction in the risk of HIV-associated morbidity and mortality. It is still unclear whether immune function ever returns to full normality. Long-term cohorts show that patients who adhere well to ART have a near-normal life expectancy. ${ }^{[1]}$

\section{Standard of care}

Maximally suppressive ART regimens should be used in HIVpositive individuals to obtain the best results and to prevent resistance. However, non-suppressive regimens have a role in HIV prevention, e.g. in the prevention of mother-to-child transmission (PMTCT) (infant prophylaxis), in post-exposure prophylaxis (PEP) for healthcare workers following certain lowrisk occupational exposures, and in pre-exposure prophylaxis (PrEP). Furthermore, these regimens are probably effective in HIV-negative individuals following low-risk sexual exposures. For further guidance see:

Southern African HIV Clinicians Society. Post-exposure prophylaxis. S Afr J HIV Med 2008;9(3):36-45. (An update will be published in 2015.) 
Table 1. Classes of ARV agents

\begin{tabular}{|c|c|c|c|}
\hline Class & Abbreviation & Mechanism of action & Specific action \\
\hline Nucleoside and nucleotide reverse transcriptase inhibitors & $\begin{array}{l}\text { NRTIs and } \\
\text { NtRTIs }\end{array}$ & $\begin{array}{l}\text { Reverse transcriptase } \\
\text { inhibition }\end{array}$ & $\begin{array}{l}\text { Nucleic acid analogues mimic } \\
\text { the normal building blocks of } \\
\text { DNA, preventing transcription } \\
\text { of viral RNA to DNA }\end{array}$ \\
\hline Non-nucleoside reverse transcriptase inhibitors & NNRTIs & $\begin{array}{l}\text { Reverse transcriptase } \\
\text { inhibition }\end{array}$ & $\begin{array}{l}\text { Alter the conformation of } \\
\text { the catalytic site of reverse } \\
\text { transcriptase and directly inhibit } \\
\text { its action }\end{array}$ \\
\hline Protease inhibitors & PIs & Protease inhibition & $\begin{array}{l}\text { Inhibit the final maturation } \\
\text { stages of HIV replication, } \\
\text { resulting in the formation of } \\
\text { non-infective viral particles }\end{array}$ \\
\hline $\begin{array}{l}\text { Integrase inhibitors } \\
\text { (also termed integrase strand transfer inhibitors) }\end{array}$ & InSTIs & $\begin{array}{l}\text { Inhibition of viral } \\
\text { integration }\end{array}$ & $\begin{array}{l}\text { Prevent the transfer of proviral } \\
\text { DNA strands into the host } \\
\text { chromosomal DNA }\end{array}$ \\
\hline Entry inhibitors & - & Entry inhibition & $\begin{array}{l}\text { Bind to viral gp } 41 \text { or gp } 120 \text { or } \\
\text { host cell CD } 4+\text { or chemokine } \\
\text { (CCR5) receptors }\end{array}$ \\
\hline
\end{tabular}

\section{Antiretroviral (ARV) agents: Classes and mechanisms of action}

There are currently five classes of ARVs available in southern Africa (Table 1). The most commonly used ARV agents inhibit one of three key HIV enzymes required by the virus for intracellular replication:

- reverse transcriptase: essential for completion of the early stages of HIV replication

- protease: required for the assembly and maturation of infectious viral progeny

- integrase: required for the integration of proviral DNA into the host chromosomal DNA.

\section{ARV agents currently available in southern Africa}

The ARV agents currently available in southern Africa are summarised in Table 2. Different fixed-dose combinations (FDCs) are increasingly being made available. The oldest combination is zidovudine (AZT)/lamivudine (3TC), but a number of other twoand three-drug FDCs are now available in the region. These FDCs reduce the burden of multiple pills and may improve treatment adherence.

\section{Indications for initiating ART}

Indications for ART initiation are summarised in Table 3. ART initiation is hardly ever an emergency, unless used for PEP or PMTCT. However, patients with profound immunosuppression are at significant risk of opportunistic infections (OIs) and associated mortality, and should be assessed rapidly and initiated on ART within $1-2$ weeks once adherence counselling has been initiated.

In patients with higher $\mathrm{CD}^{+}$counts, ART should be deferred until patients are prepared to commit to long-term treatment and are maintaining good treatment adherence. However, in eligible patients, efforts should be made to avoid lengthy indecision that may result in avoidable clinical deterioration and death.

\subsection{Rationale for these guidelines 6.1.1 CD4 ${ }^{+}$threshold}

All patients with a $\mathrm{CD} 4^{+}$count $<350$ cells $/ \mu \mathrm{L}$ should be advised and encouraged to start ART without delay. There is clinical evidence that this reduces mortality: a randomised trial in Haiti demonstrated reduced mortality and incident tuberculosis (TB) in patients starting ART at a $\mathrm{CD} 4^{+}$count threshold of $<350$ cells $/ \mu \mathrm{L}$ (compared with patients waiting to commence therapy at a threshold of $<200$ cells $/ \mu \mathrm{L}) .{ }^{[2]}$

Evidence is less clear concerning individual patient benefit when increasing the $\mathrm{CD} 4{ }^{+}$count threshold for ART initiation to 500 cells $/ \mu \mathrm{L}$. No clinical trial has shown improved patient survival from starting $\mathrm{ART}$ at a $\mathrm{CD} 4^{+}$count $>350$ cells/ $\mu \mathrm{L}$. Such trials are ongoing.

Some observational data suggest that reduced morbidity and mortality are associated with starting ART earlier (at $\mathrm{CD} 4^{+}$count thresholds of $\geq 500$ cells $/ \mu \mathrm{L}$ ). ${ }^{[3-6]}$ However, these data are derived from retrospective studies with methodological issues and probable residual confounding. If there is benefit to patients starting ART at $\mathrm{CD} 4{ }^{+}$counts $>350$ cells $/ \mu \mathrm{L}$, the benefit is likely to be small, since HIVrelated events at high $\mathrm{CD}^{+}$counts are rare. A randomised controlled trial (RCT) (HIV Prevention Trials Network 052 (HPTN052)) showed reduced morbidity but not mortality associated with starting ART at a $\mathrm{CD} 4{ }^{+}$count of $350-550$ cells $/ \mu \mathrm{L}(\mathrm{v} .<250$ cells $/ \mu \mathrm{L}) \cdot{ }^{[7]}$ However, again the absolute benefits were small. Definitive evidence regarding earlier ART initiation is awaited from ongoing RCTs, including the START (Strategic Timing of ART; http://clinicaltrials.gov/ct2/show/ NCT00867048) and TEMPRANO (Early Antiretroviral Treatment and/or Early Isoniazid Prophylaxis Against Tuberculosis in HIVinfected Adults) trials.

However, there is evidence that starting ART at higher $\mathrm{CD} 4^{+}$counts reduces HIV transmission within couples where one partner is HIVnegative (HPTN052) (see below), ${ }^{[7]}$ and wider ART coverage appears to reduce the risk of HIV transmission at a community level. ${ }^{[8]}$ Thus, consideration should be given to starting ART in patients with a $\mathrm{CD} 4^{+}$ count of $350-500$ cells $/ \mu \mathrm{L}$. However, it must be remembered that 
Table 2. Dosage and common adverse drug reactions of ARV agents available in southern Africa

\begin{tabular}{|c|c|c|c|}
\hline Generic name & Class of drug* & Recommended dosage & Common or severe $\mathrm{ADR}^{\dagger}$ \\
\hline Tenofovir (TDF) $)^{\ddagger}$ & NtRTI & $300 \mathrm{mg}$ daily & $\begin{array}{l}\text { Renal failure, tubular wasting syndrome, reduced bone } \\
\text { mineral density, hyperlactataemia/steatohepatitis (very low } \\
\text { potential) }\end{array}$ \\
\hline Lamivudine (3TC) & NRTI & $150 \mathrm{mg}$ 12-hourly or $300 \mathrm{mg}$ daily & $\begin{array}{l}\text { Anaemia (pure red cell aplasia) (rare), hyperlactataemia/ } \\
\text { steatohepatitis (very low potential) }\end{array}$ \\
\hline Emtricitabine (FTC) & NRTI & 200 mg daily & $\begin{array}{l}\text { Palmar hyperpigmentation, hyperlactataemia/ } \\
\text { steatohepatitis (very low potential) } \\
\text { Not available as a single drug in SA, only co-formulated. }\end{array}$ \\
\hline Abacavir (ABC) & NRTI & $300 \mathrm{mg}$ 12-hourly or $600 \mathrm{mg}$ daily & $\begin{array}{l}\text { Hypersensitivity reaction, hyperlactataemia/steatohepatitis } \\
\text { (very low potential) }\end{array}$ \\
\hline Zidovudine $(\mathrm{AZT})^{\ddagger}$ & NRTI & 300 mg 12-hourly & $\begin{array}{l}\text { Anaemia, neutropenia, GI upset, headache, myopathy, hyper- } \\
\text { lactataemia/steatohepatitis (medium potential), lipoatrophy }\end{array}$ \\
\hline Stavudine $(\mathrm{d} 4 \mathrm{~T})^{\ddagger}$ & NRTI & $\begin{array}{l}30 \text { mg } 12 \text {-hourly } \\
\text { Note: higher doses for }>60 \mathrm{~kg} \text { are } \\
\text { no longer recommended }\end{array}$ & $\begin{array}{l}\text { Peripheral neuropathy, lipoatrophy, hyperlactataemia/ } \\
\text { steatohepatitis (high potential), pancreatitis, HIV- } \\
\text { associated neuromuscular weakness syndrome (rare), } \\
\text { dyslipidaemia }\end{array}$ \\
\hline Didanosine $(\mathrm{ddI})^{\ddagger}$ & NRTI & $\begin{array}{l}400 \mathrm{mg} \text { daily }(250 \mathrm{mg} \text { daily if }<60 \mathrm{~kg} \text { ) } \\
\text { taken on an empty stomach (enteric- } \\
\text { coated formulation preferred) }\end{array}$ & $\begin{array}{l}\text { Peripheral neuropathy, pancreatitis, nausea, diarrhoea, } \\
\text { hyperlactataemia/steatohepatitis (high potential) }\end{array}$ \\
\hline Efavirenz (EFV) & NNRTI & $\begin{array}{l}600 \mathrm{mg} \text { at night }(400 \mathrm{mg} \text { at night } \\
\text { if }<40 \mathrm{~kg} \text { ) }\end{array}$ & $\begin{array}{l}\text { Central nervous system symptoms (vivid dreams, problems } \\
\text { with concentration, dizziness, confusion, mood disturbance, } \\
\text { psychosis), rash, hepatitis, gynaecomastia }\end{array}$ \\
\hline Nevirapine (NVP) & NNRTI & $\begin{array}{l}200 \mathrm{mg} \text { daily for } 14 \text { days then } \\
200 \mathrm{mg} \text { 12-hourly }\end{array}$ & Rash, hepatitis \\
\hline Rilpivirine (RPV) & NNRTI & $25 \mathrm{mg}$ daily with food & $\begin{array}{l}\text { Rash, hepatitis, central nervous system symptoms (all } \\
\text { uncommon) }\end{array}$ \\
\hline Etravirine (ETV) & NNRTI & 200 mg 12-hourly & Rash, hepatitis (both uncommon) \\
\hline Atazanavir (ATV) & PI & $\begin{array}{l}400 \mathrm{mg} \text { daily (only if ART-naive) or } \\
300 \mathrm{mg} \text { with ritonavir } 100 \mathrm{mg} \text { daily } \\
\text { (preferable) } \\
\text { With TDF, always } 300 / 100 \mathrm{mg} \text { daily } \\
\text { and with EFV } 400 / 100 \mathrm{mg} \text { daily }\end{array}$ & $\begin{array}{l}\text { Unconjugated hyperbilirubinaemia (visible jaundice in } \\
\text { minority of patients), dyslipidaemia (low potential), renal } \\
\text { stones (rare), hepatitis (uncommon) }\end{array}$ \\
\hline $\begin{array}{l}\text { Lopinavir/ritonavir } \\
(\mathrm{LPV} / \mathrm{r})\end{array}$ & Boosted PI & $\begin{array}{l}\text { 400/100 mg 12-hourly or } \\
800 / 200 \mathrm{mg} \text { daily (only if PI-naive). }\end{array}$ & GI upset, dyslipidaemia, hepatitis \\
\hline Darunavir (DRV) & PI & $\begin{array}{l}600 \mathrm{mg} 12 \text {-hourly with } 100 \mathrm{mg} \\
\text { ritonavir } 12 \text {-hourly or } 800 / 100 \mathrm{mg} \\
\text { daily (only if PI-naive) }\end{array}$ & $\begin{array}{l}\text { GI upset, rash, dyslipidaemia, hepatitis (uncommon) } \\
\text { Contains sulphonamide moiety (use with caution in } \\
\text { patients with sulpha allergy) }\end{array}$ \\
\hline $\begin{array}{l}\text { Saquinavir (SQV) } \\
\text { (rarely used) }\end{array}$ & PI & $\begin{array}{l}1000 \mathrm{mg} \text { with } 100 \mathrm{mg} \text { ritonavir } \\
12 \text {-hourly, or } 1600 \mathrm{mg} \text { with } 100 \mathrm{mg} \\
\text { ritonavir daily (only if PI-naive) } \\
\text { Take with a fatty meal, or up to } 2 \mathrm{~h} \\
\text { after meal }\end{array}$ & $\begin{array}{l}\text { GI disturbance (mild), hepatitis, hyperglycaemia, } \\
\text { dyslipidaemia }\end{array}$ \\
\hline $\begin{array}{l}\text { Indinavir (IDV) } \\
\text { (rarely used) }\end{array}$ & PI & $\begin{array}{l}800 \mathrm{mg} 12 \text {-hourly with } 100 \mathrm{mg} \\
\text { ritonavir 12-hourly } \\
\text { No food restrictions } \\
\text { Maintain high fluid intake }\end{array}$ & $\begin{array}{l}\text { Kidney stones, unconjugated hyperbilirubinaemia (visible } \\
\text { jaundice in minority of patients), GI disturbances, hair loss, } \\
\text { hyperglycaemia, headache, dyslipidaemia }\end{array}$ \\
\hline Raltegravir (RAL) & InSTI & 400 mg 12-hourly & $\begin{array}{l}\text { Headache, GI disturbance, hepatitis and rash (rare), } \\
\text { rhabdomyolysis (rare) }\end{array}$ \\
\hline Maraviroc (MVC) & CCR5 blocker & $\begin{array}{l}150 \mathrm{mg}, 300 \mathrm{mg} \text { or } 600 \mathrm{mg} \text { 12-hourly } \\
\text { (doses depends on concomitant } \\
\text { medication and interactions) }\end{array}$ & $\begin{array}{l}\text { Rash, hepatitis, fever, abdominal pain, cough, dizziness, } \\
\text { musculoskeletal symptoms (all rare) }\end{array}$ \\
\hline
\end{tabular}




\section{Table 2 (continued). Dosage and common adverse drug reactions of ARV agents available in southern Africa}

$\mathrm{ARV}=$ antiretroviral; $\mathrm{ADR}=$ adverse drug reaction; $\mathrm{NtRTI}=$ nucleotide reverse transcriptase inhibitor; $\mathrm{NRTI}=$ nucleoside reverse transcriptase inhibitor; $\mathrm{SA}=$ South $\mathrm{Africa} ; \mathrm{GI}=$ gastrointestinal NNRTI = non-nucleoside reverse transcriptase inhibitor; $\mathrm{PI}=$ protease inhibitor; $\mathrm{ART}=$ antiretroviral therapy; $\mathrm{InSTI}=$ integrase inhibitor (integrase strand transfer inhibit

*All PIs may be associated with cardiac conduction abnormalities (especially PR interval prolongation). This seldom results in clinically significant effects, but caution should be taken when coprescribing other drugs that cause delayed cardiac conduction, such as macrolides.

${ }^{+}$Life-threatening reactions are indicated in bold.

*ARV combinations to be avoided include:

(i) AZT + d4T (antagonism);

Wh poorer virological and immunological responses and increased toxicity): and

(iii) $\mathrm{d} 4 \mathrm{~T}+\mathrm{ddI}$ (associated with a very high risk for mitochondrial toxicities such as lactic acidosis and peripheral neuropathy).

${ }^{5}$ The following three PIs are recommended for use: LPV/r, ATV/r and DRV/r.

Patients receiving older PIs (e.g. SQV and IDV) should be switched to the recommended PIs (consult an expert if the patient's VL is not suppressed). We recommend against regimens containing dual RTV-boosted PIs, as there is no evidence for superior efficacy ${ }^{[0]}$ and more side-effects are likely.

PIs are almost always combined with RTV to boost the PI concentration. In rare situations, ATV without boosting is used in first-line therapy. Low-dose RTV is used to 'boost' the concentration of other PIs. It is always used with LPV (in FDC) and is strongly encouraged with all other PIs.

many of these patients are completely well; starting lifelong medication that needs to be taken with $100 \%$ adherence and which may have side-effects in some may be a difficult undertaking.

Consequently, we support an individualised approach in patients with a $\mathrm{CD} 4^{+}$count of 350 - 500 cells/ $\mu \mathrm{L}$ : after a discussion about the potential benefits, uncertainties, side-effects and need for impeccable adherence, patients should only be prescribed ART in this $\mathrm{CD}^{+}$ range if they are motivated for lifelong ART with the required adherence. If they do not yet feel ready, ART should be deferred until their $\mathrm{CD}^{+}$count is $<350$ cells $/ \mu \mathrm{L}$, with a plan in place for ongoing follow-up and $\mathrm{CD}^{+}$ monitoring.

Our guidance, therefore, for patients with a $\mathrm{CD}_{4}^{+}$count in the range of $350-500$ cells $/ \mu \mathrm{L}$ is that if the patient has two $\mathrm{CD} 4^{+}$ count measurements in this range and is motivated to start ART, then this therapy should be commenced. However, if the patient has a $\mathrm{CD} 4^{+}$count within this range and is not yet motivated to start lifelong ART, then the clinician can defer initiation, with follow-up and 6-monthly $\mathrm{CD} 4^{+}$monitoring planned. If the $\mathrm{CD}^{+}$count is $<350$ cells $/ \mu \mathrm{L}$, or if there is any clinical indication (Table 3), then the clinician should strongly recommend that the patient does not defer ART initiation.

\subsubsection{Treating World Health Organization stages 3 and 4}

All patients with World Health Organization (WHO) stage 3 or 4 conditions are eligible for starting ART. In particular, we advise that an episode of HIV-associated TB (i.e. TB diagnosed at the time of a seropositive HIV test) is a sufficient criterion for commencing ART, but not remote episodes of TB when the patient's HIV status was unknown. Many observational studies have shown that TB accelerates HIV disease progression and increases mortality. ${ }^{[10]}$

\section{Table 3. Indications for ART*}

Clinical diagnosis (irrespective of $\mathrm{CD}^{+}$count)

WHO clinical stage 3 and 4

ART recommended

Other severe HIV-related disorders, e.g.: ${ }^{*}$

- immune thrombocytopenia

- thrombotic thrombocytopenic purpura

- polymyositis

- lymphocytic interstitial pneumonitis

Non HIV-related disorders: ${ }^{5}$

- malignancies (excluding localised malignancies)

- hepatitis B co-infection

- hepatitis C co-infection

Any condition requiring long-term immunosuppressive therapy

\section{$\mathrm{CD}^{+}$counts}

$<350$ cells/ $\mu \mathrm{L}$

350 - 500 cells $/ \mu \mathrm{L}$ (two counts in this range)

$>500$ cells $/ \mu \mathrm{L}$

ART recommended

ART recommended

ART recommended

ART recommended

ART recommended if patient is ready and motivated to start

Defer ART

HIV-infected partner in serodiscordant relationship

Regardless of $\mathrm{CD}^{+}$count or clinical diagnoses

Offer ART and discuss safe sex (discussion should ideally involve all partners)

ART $=$ antiretroviral therapy; $\mathrm{WHO}=$ World Health Organization

${ }^{*}$ Note that EITHER listed clinical diagnoses $\mathrm{OR} \mathrm{CD} 4{ }^{+}$strata would be an indication for ART.

'See Appendix. Note that symptomatic HIV-associated nephropathy (HIVAN) is a WHO stage 4 condition and therefore a criterion for starting ART. In many settings it may be difficult to obtain a renal biopsy to confirm the diagnosis of HIVAN, and in such settings any patient with chronic renal impairment and/or significant proteinuria should be considered as eligible for ART.

"Specialist input required. Note that this list is not exhaustive - any other severe HIV-related disorder should be considered an indication for AR'T

Specialist input required. Other disorders that may benefit from improvement in immune function should also be considered as an indication to start ART. Also, given that untreated HIV appears to be a risk factor for vascular disease, patients with symptomatic vascular disease or diabetes mellitus can be considered for earlier ART.

'Hepatitis B surface antigen positive (see section 16.5 for recommended ART regimens).

\subsubsection{Serodiscordant couples}

The HPTN052 trial showed that treating the HIV-positive partner in a serodiscordant relationship with ART was associated with a $96 \%$ reduction in transmission risk to the uninfected partner ${ }^{[7]}$ Patients who do not meet other criteria for ART initiation may want to initiate ART to protect their partner(s). This should be encouraged if the patient understands the need for adherence and is motivated.

\subsection{Commencing ART in patients with TB}

Decisions regarding the timing of ART in patients with TB should be made on the basis of the $\mathrm{CD} 4^{+}$count. 
- $\mathrm{CD}^{+}$count $\leq 50$ cells/ $\mu \mathrm{L}$ : ART should be regarded as urgent, with the aim to start therapy 2 weeks following the commencement of $\mathrm{TB}$ treatment. Three $\mathrm{RCTS}{ }^{[11-13]}$ have demonstrated that this approach reduces AIDS progression and mortality. It is advised to commence ART after it is clear that the patient's TB symptoms are improving and that TB therapy is tolerated.

- $\mathrm{CD}^{+}$count $>\mathbf{5 0}$ cells/ $\boldsymbol{\mu L}$ : ART can be delayed until 8 weeks after starting TB treatment, but no later. However, if the patient has other WHO stage 4 conditions, ART should also be initiated 2 weeks after TB treatment is started. The exception to this is in the case of cryptococcal meningitis (CM) (see below; defer 4 - 6 weeks from CM diagnosis). The longer delay before commencing ART in this group is anticipated to reduce the risk of shared toxicity (as the patient will then be receiving fewer $\mathrm{TB}$ drugs) and to reduce the risk of immune reconstitution inflammatory syndrome (IRIS) (see section 18). The aforementioned RCTs did not show a higher risk of AIDS progression/ mortality in this group when ART initiation was delayed until $\sim 8$ weeks after starting TB treatment. ${ }^{[11-13]}$

- There is clinical trial evidence showing that patients with higher $\mathrm{CD} 4^{+}$ counts $(>=220$ cells $/ \mu \mathrm{L})$ can delay ART until after TB treatment completion, without excess morbidity or mortality:[14] however, in programmatic settings, the concern is that patients not initiated on ART during TB treatment may be lost to follow-up in the health system after TB treatment completion, without starting ART. For this reason, we support starting these patients on ART during TB treatment as above.

- There are important drug interactions and shared side-effects when ART is co-administered with TB therapy (section 16.1).

- When ART is commenced, patients should be warned that TB symptoms or signs may temporarily worsen and new features may occur in the first 3 months as a result of TB-IRIS.

- Unless contraindicated, co-trimoxazole (CTX) prophylaxis should be initiated in patients with HIV-associated TB.

- In patients with TB meningitis (TBM), starting ART immediately or at 2 months following diagnosis was shown to have similar high mortality, with more complications in the former. ${ }^{[15]}$ We recommend starting ART 4 - 8 weeks after TBM diagnosis.

\subsection{Starting ART in patients with other Ols and acute illnesses}

With most OIs (e.g. pneumocystis or bacterial pneumonia), if the patient has a $\mathrm{CD} 4^{+}$count $<200$ cells $/ \mu \mathrm{L}$, then the clinician should aim to start ART within 2 weeks of commencing treatment for that infection. ${ }^{[16]}$ In patients with severe Kaposi's sarcoma and lymphoma, ART counselling should be expedited and ART should be initiated as soon as possible. In a patient diagnosed with an OI in hospital, it is important to ensure referral and linkage to outpatient services for ART initiation without delay. (Refer to supplementary material: 'Starting ART in hospital' and 'High-risk patients.)

For patients with CM, the optimal time to start ART is $4-6$ weeks from the time of CM diagnosis. The COAT (Cryptococcal Optimal ART Timing) trial demonstrated $15 \%$ higher mortality in patients who started ART in hospital 1 - 2 weeks after CM diagnosis than in those starting 5 - 6 weeks after diagnosis. ${ }^{[17]}$

Regarding HIV-positive patients admitted to the intensive care unit (ICU): if the patient is receiving ART, then this should be continued (through nasogastric tube, if necessary) and only interrupted if the gastrointestinal tract is not functional (e.g. ileus); if the patient is not yet receiving ART, then it should not be commenced if the reason for admission is an acute critical illness or injury. There are several potential problems associated with commencing ART in this setting: lack of adequate counselling, gastrointestinal dysfunction, malabsorption and possible development of resistance. There are no intravenous options for an ART regimen. In patients admitted to the ICU for prolonged periods for an HIV-related condition, ART initiation in the unit should be considered after multiorgan failure has resolved.

\subsection{Patient readiness for ART}

Patient readiness for therapy is as important as the medical indications for commencing therapy.

- Conventionally, ART is not initiated at the first visit. Rather, to accommodate counselling, two or three visits are required, staggered closely together. Prolonged delays in commencing ART should be avoided. ART should be delayed only if concerns about adherence are severe enough to outweigh the risk of HIV disease progression.

- The patient should be provided with details on the following key information:

- the benefits of ART

- that ART is life-long therapy

- the importance of good adherence

- a list of ART side-effects, including what to do and who to contact if serious side-effects occur.

- Active depression or substance abuse should actively be detected and treated.

- A personal treatment plan should be formulated for each patient, specifying drug storage, strategies for missed doses and how to integrate taking medication into their daily routine. The patient must be made aware of scheduling in terms of clinical follow-up.

- Disclosure of HIV status (to a partner and/or other household members) should strongly be encouraged. This has been shown to be an important determinant of treatment adherence and assists in the provision of patient-directed support. Disclosure also identifies exposed contacts for screening and support. This issue needs to be handled sensitively in situations where disclosure may have harmful consequences, particularly for women.

- The patient should be encouraged to join a support group and/or identify a treatment 'buddy.' However, neither disclosure nor support group participation are prerequisites for good adherence in all patients, and should not be a reason for deferring ART.

- Clinicians should ensure that they have the contact details of each patient and their treatment buddy.

- Counselling should cover safe-sex practices and address issues related to reproductive health (i.e. family planning, contraception, condom use, pregnancy and PMTCT).

(Refer to supplementary material: 'Common ART misconceptions', and 'Practical measures for monitoring and enhancing adherence and retention in care'.)

\subsection{ART in primary HIV infection}

Several recent studies have suggested that starting ART during seroconversion is associated with slower subsequent disease progression. A subgroup of patients who started ART during seroconversion and were treated for 3 years showed virological control for several years after interrupting ART. ${ }^{[18]}$ We recommend initiating standard first-line therapy in patients diagnosed during seroconversion, if adherence requirements are met. ART should be continued for at least 3 years, but consideration should be given to continuing lifelong 
ART in these patients. Commencing therapy during seroconversion is likely to limit the size of the HIV reservoir. Diagnosing seroconversion is facilitated by having a recent negative HIV test that then becomes positive on a subsequent test. Otherwise, the following are suggestive: the compatible clinical syndrome, an indeterminate enzyme-linked immunosorbent assay (ELISA) test result that then becomes positive on a subsequent test, and a very high $\mathrm{VL}$.

\section{Investigations prior to starting ART}

The following investigations are recommended prior to initiating ART:

- alanine transaminase (ALT)

- full blood count (FBC): avoid AZT if haemoglobin ( $\mathrm{Hb})$ is $<8 \mathrm{~g} / \mathrm{dL}$

- serum creatinine and calculation of creatinine clearance $(\mathrm{CrCl})$ : avoid tenofovir (TDF) if $\mathrm{CrCl}$ is $<50 \mathrm{~mL} / \mathrm{min}$; other nucleoside reverse transcriptase inhibitors (NRTIs), except abacavir ( $\mathrm{ABC})$, require dose adjustment if $\mathrm{CrCl}$ is $<50 \mathrm{~mL} / \mathrm{min}$ (either using the estimated glomerular filtration rate (eGFR) provided by the laboratory or calculating using the modified Cockgraft-Gault equation, Table 9)

- urinalysis for proteinuria

- hepatitis B surface antigen (HBsAg)

- $\mathrm{CD} 4^{+}$count

- baseline VL

- syphilis serology

- serum cryptococcal antigen test in patients starting ART at a CD4 $4^{+}$ count $<100$ cells $/ \mu \mathrm{L}$ (to screen for early cryptococcal disease and to initiate pre-emptive treatment if positive).

If HIV diagnosis has been made using two rapid tests performed outside of a laboratory setting, then we advise confirming the positive serostatus using a laboratory test prior to commencing lifelong ART. A detectable VL result would be sufficient (note that it may be undetectable in $<1 \%$ of patients not receiving ART, i.e. 'elite controllers'), but if unaffordable/unavailable, then an ELISA should be performed.

\section{Initial ART regimens for the previously untreated patient}

The preferred first-line regimen is TDF + emtricitabine (FTC) (or 3TC) + efavirenz (EFV). There are situations where this regimen cannot be used and these are discussed below.

\subsection{NNRTI component of first-line regimen}

In accordance with international recommendations, we recommend the use of a non-nucleoside reverse transcriptase inhibitor (NNRTI) and two NRTIs as the first-line ART regimen. In comparison with protease inhibitors (PIs), NNRTIs are better tolerated in the long term and are at least as potent when combined with an appropriate dual NRTI combination. ${ }^{[19]}$ In addition, we do not recommend PIs in firstline therapy owing to the associated cost and role in subsequent lines of therapy. For the same reasons, we do not recommend integrase inhibitors (integrase strand transfer inhibitors (InSTIs)) in first-line therapy. However, intolerance or contraindications to NNRTIs may dictate their use. An affordable InSTI-based first-line regimen may feature in future guidelines. However, in the interests of harmonising public and private sector guidelines, our opinion is that NNRTI first-line regimens are currently preferable. Many patients transition between the two sectors, and we have advised the use of InSTI in third-line therapy, as used in the public sector.
Either EFV, rilpivirine (RPV) or nevirapine (NVP) may be selected as the NNRTI; EFV is preferred. Owing to its neuropsychiatric sideeffects, EFV should be avoided in those with active psychiatric illness or a history of severe psychiatric disease, in night-shift workers and in those operating heavy machinery or industrial vehicles. NVP should be avoided in women with a CD $4^{+}$count $>250$ cells $/ \mu \mathrm{L}$ and men with a CD $4^{+}$ count $>400$ cells $/ \mu \mathrm{L}$ who are initiating ART for the first time, because of the increased risk of rash-associated hepatitis. It should be noted, however, that this side-effect can occur with any $\mathrm{CD} 4^{+}$count. Clinicians should consider avoiding NVP in patients who may encounter difficulties obtaining rapid medical attention should rash or hepatitis symptoms occur. NVP should also be avoided in patients with pre-existent liver disease. RPV should not be used in patients with a VL $>100000$ copies/ $\mathrm{mL}$, as clinical trials have shown that RPV-based regimens have higher virological failure rates in patients with higher VLs compared with EFVbased regimens. ${ }^{[20]}$ In patients with a VL $\leq 100000$ copies $/ \mathrm{mL}$, outcomes are comparable overall with EFV-based regimens, with RPV being better tolerated. ${ }^{[21]}$ When EFV, NVP and RPV are contraindicated (e.g. after a life-threatening NNRTI hypersensitivity reaction), raltegravir (RAL) or a PI could be substituted. Any patient starting an NNRTI should be told to report a rash, jaundice or symptoms of hepatitis immediately.

A $400 \mathrm{mg}$ dose of EFV was non-inferior in terms of virological suppression compared with a $600 \mathrm{mg}$ dose in the ENCORE trial. ${ }^{[22]}$ If there are significant non-resolving central nervous system side-effects, then the clinician should consider reducing the dose to $400 \mathrm{mg}$. A drawback of this is that there are no FDCs containing $400 \mathrm{mg}$ of EFV. This EFV dose reduction should not be done for patients receiving TB treatment or who are pregnant, as the efficacy of this dose has not been studied in these patient groups (EFV concentrations are reduced in pregnancy).

Etravirine (ETV) use is not advised in first-line regimens, as this has not been studied in RCTs and the drug has many significant drug interactions.

\subsection{NRTI component of first-line regimen}

Any of the following two-drug NRTI combinations are recommended for use with the NNRTI:

- TDF + emtricitabine (FTC - a cytidine analogue very similar to 3TC - is combined with TDF in an FDC or with the addition of EFV as a triple-drug combination pill)

- $\mathrm{TDF}+3 \mathrm{TC}$

- $\mathrm{ABC}+3 \mathrm{TC}$

We favour regimens that include FDCs and allow once-daily dosing.

TDF is the favoured NRTI to use with 3TC or FTC, as it aligns with public sector programmes, is widely available as an FDC, and is very well tolerated. However, patients with a $\mathrm{CrCl}<50 \mathrm{~mL} / \mathrm{min}$ should not start TDF and should rather start ABC. Certain clinical trials suggest that $\mathrm{ABC}$-containing (v. TDF-containing) first-line regimens are associated with lower rates of virological suppression in patients with a baseline VL $>100000$ copies/mL. ${ }^{[23,24]}$ However, a recent meta-analysis shows that virological suppression is equivalent with ABC- and TDF-containing first-line regimens regardless of baseline $V_{L}{ }^{[25]}$ Given this finding, we now recommend that $\mathrm{ABC}$ can be used in patients with a $\mathrm{VL}>100000$ copies/mL, without concerns regarding virological efficacy. $\mathrm{ABC}$ has been associated with an increased risk of myocardial infarction in some cohort studies, ${ }^{[26,27]}$ but the association was not confirmed in a meta-analysis of RCTs. ${ }^{[28]}$ Nevertheless, caution 
is recommended when considering $\mathrm{ABC}$ for patients at significant risk of, or with established ischaemic heart disease. $\mathrm{ABC}$, which does not require dose adjustment in renal failure, is specifically recommended for use in chronic renal failure, as TDF is nephrotoxic and AZT could aggravate the anaemia of renal failure.

We now recommend that AZT or short-term stavudine ( $\mathrm{d} 4 \mathrm{~T})$ are only used in special circumstances in first-line therapy. If both TDF and $\mathrm{ABC}$ are unavailable or contraindicated, then AZT should be used, provided that the $\mathrm{Hb}$ level is $>8 \mathrm{~g} / \mathrm{dL}$. As it is considerably more toxic than other NRTIs, $\mathrm{d} 4 \mathrm{~T}$ is no longer recommended. Nonetheless, there is still a role for $\mathrm{d} 4 \mathrm{~T}$ in selected patients, when it is used in the short term in patients with contraindications to other NRTIs. A common example is a patient with renal dysfunction and anaemia at baseline, who could be initiated on $\mathrm{d} 4 \mathrm{~T}$ for $3-6$ months if $\mathrm{ABC}$ is unavailable, and then switched to AZT or TDF depending on resolution of the anaemia and/or renal dysfunction. In addition, if there is a need for concomitant nephrotoxic medications, e.g. aminoglycosides to treat multidrug-resistant (MDR)$\mathrm{TB}$, then $\mathrm{ABC}, \mathrm{AZT}$ or short-term $\mathrm{d} 4 \mathrm{~T}$ are preferable to TDF during the period of exposure to the other nephrotoxic medication. Patients usually tolerate short-term d4T well. Severe $\mathrm{d} 4 \mathrm{~T}$ side-effects, such as hyperlactataemia, lipoatrophy and other mitochondrial toxicities, typically occur after 6 months, although peripheral neuropathy can develop earlier.

\section{Laboratory monitoring for ART efficacy}

\section{$9.1 \mathrm{VL}$}

\subsubsection{Timing of $V L$ monitoring}

VL monitoring should be performed:

- at baseline (before commencing ART)

- at 3 months after the commencement of ART (This early VL is desirable to detect adherence problems early, before resistance develops. A subset of patients who start with a very high VL may not be fully suppressed at 3 months despite $100 \%$ adherence, but such patients would have had a $>2 \log _{10}$ drop in VL from baseline; therefore, the 3-month result should be interpreted in relation to the baseline VL. All patients who have a detectable VL at 3 months should receive additional adherence interventions.)

- at 6 months and thereafter every 6 months. (In patients who have an undetectable VL for $>12$ months, and who demonstrate reliable adherence and follow-up, it may be acceptable to reduce the frequency of VL monitoring to annually.)

If $\mathrm{VL}$ is $>50$ copies $/ \mathrm{mL}$, then the patient should receive counselling and interventions should be implemented to improve adherence. A repeat measurement of VL should then be done in 2 - 3 months.

\subsubsection{Interpreting VL results}

A VL $>50$ copies $/ \mathrm{mL}$ while receiving ART should be an indication for urgent action to improve adherence. A subsequent ART change must be considered if the patient meets the criteria for a switch to a second-line ART regimen at the subsequent 2 - 3-month follow-up VL measurement (section 11, 'Indications for changing ART').

VL monitoring is key to the success of ART. Decisions to change ART made on the basis of virological failure, rather than on clinical or immunological failure alone, result in better patient outcomes. If the VL is undetectable, then the virus cannot mutate and develop resistance. A sustained VL of $<50$ copies $/ \mathrm{mL}$ is associated with the most durable benefit.
Isolated detectable HIV VLs that are $<1000$ copies $/ \mathrm{mL}$, which are followed by an undetectable VL, are termed 'viral blips' and do not indicate an increased risk of virological failure.

\subsection{CD4 ${ }^{+}$counts}

$\mathrm{CD} 4^{+}$counts should be performed every 6 months. In patients being monitored with VL measurements, once the $\mathrm{CD} 4^{+}$count is $>200$ cells $/ \mu \mathrm{L}$, provided that the $\mathrm{VL}$ is suppressed, routine $\mathrm{CD} 4^{+}$testing can be stopped, as it adds little to management. Data to support this have recently been summarised. ${ }^{[29]}$ However, if virological or clinical failure occurs, then a $\mathrm{CD} 4^{+}$count should be repeated, as CTX prophylaxis should be commenced if the count falls to $<200$ cells $/ \mu \mathrm{L}$ while receiving ART.

\section{Defining ART failure}

In resource-limited settings where VLs are unavailable, the WHO has devised criteria for defining ART failure on the basis of $\mathrm{CD}^{+}$ count responses or clinical disease progression. Studies have shown that switching ART regimens using these criteria results in a significant proportion of patients switching very late (with progressive accumulation of resistance mutations) and switching inappropriately (as the $\mathrm{CD} 4^{+}$count response may be poor in some patients, despite optimal virological suppression). ${ }^{[30]}$

\subsection{Virological criteria for treatment success}

Treatment success is defined by:

- a decline in VL of at least $2 \log _{10}$ from pretreatment levels 3 months after initiating ART

- a decline in VL to $<50$ copies $/ \mathrm{mL}$ within 6 months of commencing ART, and sustained thereafter.

\subsection{Virological criteria for treatment failure}

Treatment failure is defined by a confirmed VL of $>1000$ copies $/ \mathrm{mL}$ in two measurements taken 2 - 3 months apart. Several factors can influence the measurement of the VL. The decision to alter ART should therefore be based on the results of repeat testing after $2-3$ months, following intensive adherence counselling. Inadequate patient adherence to the prescribed regimen remains the most common reason for treatment failure. Other important causes include: prior use of single-dose NVP for PMTCT; drug interactions that decrease ART concentrations; and transmitted drug resistance, which is currently uncommon in the region $(<5 \%){ }^{[31]}$

\section{$10.3 \mathrm{CD}^{+}$response}

Typically, the $\mathrm{CD} 4^{+}$count increases rapidly in the first month of ART, by approximately $75-100$ cells $/ \mu \mathrm{L}$, with a more gradual rise thereafter $(50-100 \text { cells/ } / \mathrm{L} / \text { year })^{\left[{ }^{[32]}\right.}$ Most, but not all, patients achieve a $\mathrm{CD} 4^{+}$ count $>500$ cells $/ \mu \mathrm{L}$ after several years of ART, provided that the VL remains suppressed. ${ }^{[33-35]}$ However, $\mathrm{CD}^{+}$responses are highly variable and may fail to increase despite virological suppression in about $10-20 \%$ of patients. ${ }^{[3,37]}$ Such patients have a delayed or absent $\mathrm{CD}^{+}$response to ART despite viral suppression, which is termed an 'immunological discordant response to ART'. Certain studies suggest that older patients are at higher risk. There is no evidence that such patients benefit from a change in ART regimen; therefore, the same regimen should be continued. CTX prophylaxis should be continued if the $\mathrm{CD}^{+}$count remains $<200$ cells/ $\mu \mathrm{L}$. There is evidence that the prognosis of such patients is worse than in those who have a $\mathrm{CD} 4^{+}$ 
response, but better than that of patients not receiving ART. If patients with an immunological discordant response to ART are clinically unwell, then TB or lymphoma should be considered as the cause of persistent $\mathrm{CD} 4^{+}$lymphopenia.

$\mathrm{CD} 4^{+}$counts may continue to rise or remain stable in the presence of incomplete viral suppression (which will result in the emergence of drug resistance) in patients receiving PI-based ART until the VL is high (approximately $\geq 10000$ copies $/ \mathrm{mL}$ ). ${ }^{[38}$

\section{Indications for changing ART}

Individual ART drugs may be substituted in the event of toxicity (section 17), provided that the VL is suppressed or ART was initiated within the preceding 6 months. Changing the first-line ART regimen to a second-line regimen is a major step. The drugs used in secondline regimens are often not as well tolerated and are more expensive. For this reason, clinicians tend to switch to second-line ART after a prolonged period of virological failure, causing a progressive increase in the accumulation of resistance mutations. If the VL is detectable, it is essential to step up adherence interventions, as discussed above. We advise a switch to a second-line regimen without undue delay when two VL measurements have been $>1000$ copies $/ \mathrm{mL}$, preferably with the measurements taken 2 - 3 months apart, with at least 4 weeks of an intensified adherence intervention in between. In patients with low $\mathrm{CD} 4^{+}$ counts $(<100$ cells $/ \mu \mathrm{L})$, this process should be expedited.

Some patients have persistently detectable VLs at low levels (200 1000 copies $/ \mathrm{mL}$ ). If patients have low-level viraemia for a prolonged period ( $>1$ year), or persistently low $\mathrm{CD}^{+}$counts $(<100$ cells $/ \mu \mathrm{L})$ together with low-level viraemia despite adherence interventions, then they should be switched to second-line ART.

\section{Second-line ART regimens 12.1 Resistance testing for selecting second- line ART}

A resistance test at first-line failure should be considered if resources permit. However, in many settings in the region, this is unaffordable and/or unavailable. The benefits of such testing include that it may be able to differentiate between adherence problems (when the resistance test shows no resistance mutations) and the development of resistance, and may be informative regarding ETV or RPV mutations in subsequent third-line regimens. It will help in deciding which NRTIs to use in second-line therapy, although the recently published EARNEST (Europe-Africa Research Network for Evaluation of Secondline Therapy) trial shows that even without the use of a resistance test to decide upon which NRTIs to use in second-line therapy, virological outcomes are good and equivalent to a PI + RAL regimen. ${ }^{[39]}$

\subsection{Recommended second-line ART regimen}

We recommend a regimen of two NRTIs and a ritonavir (RTV)-boosted (/r) PI. Boosting of PIs involves the addition of low-dose RTV, which inhibits PI metabolism, thereby boosting PI plasma concentration and prolonging half-life. We recommend against the use of unboosted PIs.

\subsection{RTV-boosted PI in the second-line regimen}

Based on clinical trials demonstrating superior tolerability, ${ }^{[40,41]}$ we suggest that the preferred PI in second-line therapy should be atazanavir (ATV) $300 \mathrm{mg} / \mathrm{RTV} 100 \mathrm{mg}$ daily. The benefits of ATV/r over lopinavir
$(\mathrm{LPV}) / \mathrm{r}$ include that it is better tolerated in terms of gastrointestinal side-effects, has a more favourable lipid profile, and is taken once daily. Drawbacks of ATV/r are: it cannot be used with rifampicin (RIF)-based TB treatment; there is no FDC containing RTV registered in SA; RTV capsules are not heat stable; and there are important drug interactions with drugs that reduce stomach acidity such as proton pump inhibitors. An alternative RTV-boosted PI rather than ATV/r should be used in the following situations:

- patients who do not tolerate ATV/r (e.g. cosmetically unacceptable jaundice): use LPV/r

- patients who do not own a fridge (to store RTV capsules): use LPV/r - patients receiving RIF-based TB treatment: double-dose LPV/r should be used while receiving the TB treatment.

Other RTV-boosted PI options in second-line therapy are LPV/r and darunavir (DRV)/r. LPV is coformulated with RTV in a heat-stable tablet (Aluvia) and is the better option in patients without a refrigerator (other PIs require RTV-boosting with a separate RTV capsule that ideally requires refrigeration, although RTV capsules are stable at room temperature for 30 days). This is also an option with RIF when doubledosed.

$\mathrm{DRV} / \mathrm{r}$ is taken twice daily, currently, and is more costly. When the $400 \mathrm{mg}$ formulation becomes available, the $800 / 100 \mathrm{mg}$ daily dose will be a feasible option in second-line ART, with fewer side-effects than the twice daily dosing.

Indinavir (IDV) is significantly more toxic than other PIs. Saquinavir (SQV) is less robust in terms of resistance than the three options listed. IDV and SQV confer no benefit over other options, and are therefore not recommended.

\subsection{Selecting second-line dual NRTIs}

Because boosted PIs are robust drugs (i.e. resistance develops slowly) in PI-naive patients, it is very likely that virological suppression will be achieved with good adherence, even if the two NRTIs used in secondline therapy are partially compromised by NRTI resistance mutations (Tables 4 and 5) ${ }^{[42]}$ This is supported by findings of the EARNEST trial, which showed good virological suppression rates of second-line LPV/r and NRTI regimens, even in patients with significant NRTI resistance. ${ }^{[39]}$

Certain NRTI combinations are contraindicated for toxicity reasons (e.g. $\mathrm{d} 4 \mathrm{~T}+$ didanosine (ddI), or TDF + ddI). TDF + ABC is not recommended for second-line ART, as these agents share resistance mutations. NRTI combinations advised for second-line regimens include either AZT + 3TC, or TDF + 3TC (FTC can be substituted for 3TC), depending on the likely mutational profile selected during the patient's first-line NRTI combination.

Even if 3TC (or FTC) was used in a failed first-line regimen and may, therefore, have selected for the M184V mutation, which confers resistance to the agent, 3TC (or FTC) can be reused in second-line therapy because of the capacity of the $\mathrm{M} 184 \mathrm{~V}$ mutation to partially restore susceptibility to AZT, d4T and TDF in the presence of thymidine analogue mutations (TAMs), and to partially restore susceptibility to TDF in the presence of the K65R mutation. The M184V mutation also reduces the replicative capacity of the virus.

\subsection{Selecting second-line ART in patients who received a first-line $\mathrm{PI}$ regimen}

If a patient was receiving a first-line combination of two NRTIs and a PI (boosted or unboosted), it is best to discuss the choice of second-line 
regimen with an experienced HIV clinician, and to perform a genotype resistance test. Second-line NNRTI + NRTI regimens are often not effective in such patients because of NRTI resistance mutations. The regimen choice is therefore best guided by resistance testing.

\section{Third-line ART regimens}

Third-line ART (also referred to as 'salvage' therapy) is used when a patient has experienced virological failure on drugs from the NRTI, NNRTI and PI classes, and has documented PI resistance. Before considering third-line therapy, adherence interventions should be intensified, and then adherence checked (e.g. check that pharmacy refills are all collected over a 6-month period). If there is still no viral suppression, then a resistance test should be performed to confirm the presence of resistance to the PI being used in secondline therapy. We advise doing this only after patients have been on a PI-based second-line regimen for a period of longer than 1 year, as the development of resistance earlier than this is very uncommon, unless there has been a medication error (e.g. giving standarddose LPV/r with RIF). The resistance test is very expensive and the patient must be receiving the failing ART at the time, as 'wild-type' HIV is more fit and outgrows the resistant mutant population which therefore cannot be detected within some weeks after cessation of ART. However, third-line regimens are also extremely expensive and are not justified if the patient does not have resistance necessitating such a switch. Currently, data show that most patients failing secondline regimens in the SA public sector have no PI mutations. In these patients, improved adherence is required rather than third-line regimens. The decisions regarding treatment choices in third-line therapy are complex and need to be guided by resistance patterns found on resistance testing. It is essential that resistance tests are interpreted by an expert in conjunction with a full ART history.

In recent years, a number of new drugs for use in third-line ART have become available (e.g. InSTIs together with newer PIs (darunavir (DRV) and tipranavir (TPV)) and NNRTIs (ETV and RPV)). ${ }^{[43]}$ These provide an opportunity for effective viral suppression with third-line therapy in the majority of patients, provided that adherence is optimal. DRV, ETV, RPV, RAL (an InSTI) and maraviroc (MVC) are now registered in SA. No firm recommendations for a generic third-line regimen can be made and regimen choice should be individualised. An expert treater should always be consulted. A few guidelines regarding third-line ART regimens are:

- There is a need for specific adherence counselling in patients preparing to start third-line ART, with a frank discussion that this regimen is likely to be their last option for the foreseeable future.

- First-generation NNRTIs (NVP and EFV) have no place in third-line therapy as they do not impair viral fitness.

- A boosted PI with the broadest resistance profile should be selected (this is currently DRV). ${ }^{[4]}$ DRV must be used twice daily in this context (600 mg 12-hourly with $100 \mathrm{mg}$ RTV 12-hourly). LPV may be used if the drug is still active based on a resistance test (e.g. if the patient failed second-line ATV therapy).

- The addition of 3TC (or FTC) is recommended as the M184V mutation that it selects for impairs viral replication. Other NRTIs (the most active based on resistance testing) should also be added.

- Consideration of the addition of other salvage drugs (e.g. RAL ${ }^{[45]}$ and/ or $\mathrm{ETV}^{[46,47]}$ or RPV) will depend on the results of genotype resistance testing and cost issues. RAL is preferred because it belongs to an entirely new class with no risk of cross-resistance from prior ART exposure in first- and second-line therapy. Because most patients are not receiving an NNRTI at the time of failing second-line therapy when a genotype resistance test is typically performed, prior NNRTI mutations related to first-line NNRTI failure may be archived at this time. Therefore, it is difficult to be certain from this genotype whether ETV is compromised; however, data from SA suggest that the majority of patients who have failed NVP or EFV are still susceptible to ETV. ${ }^{[48]}$

- We advise against double RTV-boosted PIs. ${ }^{[9]}$

- If viral suppression is not achieved on salvage therapy, then there is still benefit in continuing failing ART, because of the residual partial activity and 'crippling' effect of such ART. 'Crippling' describes the fact that mutant viruses often have less replicative capacity. Provided that the VL can be maintained at $<10000$ copies $/ \mathrm{mL}$, the $\mathrm{CD} 4^{+}$count will usually be maintained or even increase. ${ }^{[38]}$

- MVC (a CCR5 blocker) is a consideration for salvage therapy; however, it is currently extremely costly and can only be used after a tropism test demonstrates that the patient's circulating virus has sole tropism for the CCR5 coreceptor. We advise only considering this for a salvage regimen when there is intermediate- or high-level resistance to all PIs, all NNRTIs and all NRTIs.

For further guidance, consult the Southern African HIV Clinicians Society ART resistance guideline:

Southern African HIV Clinicians Society. The 2012 Southern African ARV drug resistance testing guidelines. S Afr J HIV Med 2012;13(4):162-167.

\subsection{Stopping ART}

Structured treatment interruptions are not advised as they have been shown to increase mortality (SMART study). ${ }^{[49]}$ Sometimes, patients need to stop therapy for reasons beyond the control of the patient and clinician. If life-threatening toxicity occurs (e.g. hepatitis with liver failure), all drugs should be stopped at once, but in most cases of toxicity, a continuation of ART should be attempted while switching the culprit drug to an alternative. If stock-outs occur, it may also be necessary to stop ART. With PI and InSTI regimens, it is possible to stop all drugs simultaneously. With an NNRTI regimen, it is necessary to cover the tail with 5 - 7 days of two NRTIs (not needed if TDF/FTC are the NRTIs).

We advise against 3TC monotherapy 'holding regimens' in patients who have virological failure. Such regimens can be associated with a rapid fall in $\mathrm{CD} 4^{+}$count. The objective when prescribing ART should always be to provide a regimen that is most likely to achieve virological suppression.

\section{Patients who return after defaulting therapy}

We recommend restarting the same regimen if patients return to care after defaulting therapy. A VL should preferably be performed before restarting. We then recommend that the VL is measured 3 months after restarting ART; switching to a second-line regimen should be considered if the $\mathrm{VL}$ is not $<1000$ copies $/ \mathrm{mL}$ at this point. In patients with multiple episodes of interruption, particularly beyond the first year of ART, many clinicians would consider switching to a secondline regimen, making the assumption that the multiple interruptions resulted in first-line resistance. Reasons for defaulting should be addressed and adherence support increased. 
Table 4. Mutations selected by first-line NRTI combinations*

\begin{tabular}{|c|c|}
\hline First-line NRTIs & NRTI mutations selected \\
\hline 3TC or FTC & $\begin{array}{l}\text { Select for M184V, which compromises both } 3 \mathrm{TC} \text { and FTC, and slightly impairs the activity of ABC and ddI, but } \\
\text { increases susceptibility to AZT, d } 4 \mathrm{~T} \text { and TDF }\end{array}$ \\
\hline AZT & Selects for TAMs, which may compromise all NRTIs ${ }^{\dagger}$ \\
\hline $\mathrm{d} 4 \mathrm{~T}$ & $\begin{array}{l}\text { Selects for TAMs, which may compromise all NRTIs } \\
\text { In a minority of patients, d4T may select for K65R, which compromises TDF, ABC and ddI, but increases susceptibility } \\
\text { to AZT }\end{array}$ \\
\hline TDF & Selects for K65R, which compromises TDF, ABC and ddI, but increases susceptibility to AZT \\
\hline $\mathrm{ABC}$ & $\begin{array}{l}\text { Selects for L74V, which compromises } \mathrm{ABC} \text { and ddI } \\
\text { May also select for K65R, which compromises TDF, ABC and ddI, but increases susceptibility to AZT } \\
\text { Selects for Y115F, which decreases its susceptibility }\end{array}$ \\
\hline \multicolumn{2}{|c|}{$\begin{array}{l}\mathrm{NRTI}=\text { nucleoside/nucleotide reverse transcriptase inhibitor; } 3 \mathrm{TC}=\text { lamivudine; } \mathrm{FTC}=\text { emtricitabine; } \mathrm{ABC}=\text { abacavir; } \mathrm{ddI}=\text { didanosine; } \mathrm{AZT}=\text { zidovudine; } \mathrm{d} 4 \mathrm{~T}=\text { stavudine; } \mathrm{TDF}=\text { tenofovir; } \mathrm{TAMs}= \\
\text { thymidine analogue mutations. }\end{array}$} \\
\hline
\end{tabular}

\section{Table 5. Choice of second-line NRTIs in relation to first-line NRTIs used}

\begin{tabular}{|c|c|}
\hline First-line NRTIs used & Second-line NRTI combination advised \\
\hline $\mathrm{AZT}+3 \mathrm{TC}$ & $\mathrm{TDF}+3 \mathrm{TC}^{*}$ \\
\hline $\mathrm{d} 4 \mathrm{~T}+3 \mathrm{TC}$ & $\begin{array}{l}\mathrm{TDF}+3 \mathrm{TC}^{*} \text { (preferably genotype first, } \\
\text { given the increased risk of K65R on } \mathrm{d} 4 \mathrm{~T} \\
\text { in subtype } \mathrm{C}^{[50]} \text { ) }\end{array}$ \\
\hline $\mathrm{TDF}+3 \mathrm{TC}^{*}$ & $\mathrm{AZT}+3 \mathrm{TC}$ \\
\hline $\mathrm{ABC}+3 \mathrm{TC}$ & $\mathrm{AZT}+3 \mathrm{TC}$ \\
\hline \multicolumn{2}{|c|}{$\begin{array}{l}\text { NRTIs = nucleoside reverse transcriptase inhibitors; } \mathrm{AZT}=\text { zidovudine; } 3 \mathrm{TC}=\text { lamivudine; } \\
\text { TDF = tenofovir; } \mathrm{d} 4 \mathrm{~T}=\text { stavudine; } \mathrm{ABC}=\text { abacavir; } \mathrm{FTC}=\text { emtricitabine. }\end{array}$} \\
\hline${ }^{*} 3 \mathrm{TC}$ is interchangeable with FTC & \\
\hline
\end{tabular}

Hospitalisation with an AIDS-defining condition and a CD4 $4^{+}$count of $<50$ cells $/ \mu \mathrm{L}$ represents another situation where a patient may be restarted immediately on second-line ART when returning to care after defaulting; the reason being that the patient is considered to be at high risk of mortality if restarted on a first-line therapy to which their virus may be resistant, and that they require a guaranteed effective ART regimen immediately. This decision should usually be taken by the clinicians at a hospital level.

Performing a resistance test after the patient has been off ART for longer than 4 weeks is of limited value, as many resistance mutations are overtaken by wild-type virus when ART is stopped.

\section{Drug interactions}

There are many important drug interactions between ARV agents and other medications, as well as between certain ARV agents themselves. These interactions occur because of the metabolism of ARV drugs by cytochrome $\mathrm{P} 450$ in the liver and intestine, and the induction or inhibition of ARVs by this and other enzyme systems and drug transporters. Some of these drug interactions are discussed in these guidelines (e.g. the interaction between RIF and NNRTIs, PIs and RAL). The list of all potential drug interactions is, however, very long and beyond the scope of this document. Knowledge of drug interactions is constantly evolving. Clinicians are advised to consult the package inserts of ARV agents and concomitant medications to assess for drug interactions, in addition to the following websites, which provide up-to-date information on drug interactions and the actions required to account for them:
- University of Liverpool Drug Interactions Charts: http://www.hiv-druginteractions.org

- University of Cape Town Medicines Information Centre ARV interactions table:

http://www.mic.uct.ac.za/?page_id=47

We advise that clinicians assess for potential drug interactions whenever patients start or switch to new ARV drugs or regimens, and start new concomitant medications. In addition, herbal medications may also have interactions with ARVs.

\section{ART in special populations 16.1 TB}

The ART regimen should be modified if necessary for compatibility with RIF. RIF is a critical component of the TB regimen that substantially reduces the risk of relapse after completing TB treatment. EFV is the preferred NNRTI for use with RIF. NVP is an alternative in patients with contraindications for EFV (e.g. psychosis), but it carries a higher risk of hepatitis and virological failure when used with RIF.

The plasma concentrations of all boosted PIs are reduced to subtherapeutic ranges with RIF. Dose adjustment of LPV/r can overcome this induction (Table 6), but there is a risk of hepatotoxicity. The patient will require counselling and ALT should be monitored frequently.

An alternative approach is to replace RIF with rifabutin (RFB). However, RFB is expensive and not currently widely available at public sector TB clinics. Also, RFB is not coformulated with other $\mathrm{TB}$ drugs, and the evidence base for RFB in the treatment of TB is much less substantial than that for RIF. ${ }^{[1]}$ There is also uncertainty regarding the optimal dose of RFB with boosted PIs; these guidelines recommend $150 \mathrm{mg}$ on alternate days (Table 7). RFB may be considered in patients who are not tolerating cotreatment with LPV/r and RIF-based antitubercular therapy (patients unable to tolerate the increased LPV/r dose due to hepatotoxicity or gastrointestinal side-effects) or in ART-experienced patients on an ART regimen that is not compatible with RIF (e.g. third-line ART with DRV/r). If $\mathrm{RFB}$ is unavailable and adjusted doses of LPV/r are poorly tolerated in patients receiving second-line ART, then RAL may be substituted for the PI or triple NRTI therapy may be considered. Triple NRTI $\mathrm{ART}$ is, however, inferior to conventional ART, and RAL is less 
Table 6. ART interactions with RIF and recommendations for co-administration

\begin{tabular}{|c|c|c|c|}
\hline Class & ARV agent & Interaction & Dose of ART drug with RIF \\
\hline NRTI & All in class & No significant pharmacokinetic interactions & No dose adjustment required \\
\hline \multirow[t]{3}{*}{ NNRTI } & $\mathrm{EFV}$ & $\begin{array}{l}\text { Mild reduction in EFV concentrations } \\
\text { In some patients on TB treatment, EFV concentrations } \\
\text { may increase }\end{array}$ & No dose adjustment required (600 mg nocte) \\
\hline & NVP & $\begin{array}{l}\text { Moderate reduction in NVP concentrations with increased } \\
\text { risk of virological failure compared with EFV }\end{array}$ & $\begin{array}{l}\text { Use standard dosing, but omit the lead-in dose phase } \\
\text { and start } 200 \text { mg NVP 12-hourly }\end{array}$ \\
\hline & $\begin{array}{l}\text { ETV and } \\
\text { RPV }\end{array}$ & Marked reduction in concentrations & Do not prescribe concomitantly with RIF \\
\hline \multirow[t]{2}{*}{ PI } & $\mathrm{LPV} / \mathrm{r}$ & LPV plasma concentrations significantly decreased & $\begin{array}{l}\text { The preferable strategy is to double the dose of LPV/r } \\
\text { to } 800 / 200 \mathrm{mg} 12 \text {-hourly } \\
\text { Alternatively, add } 300 \mathrm{mg} \text { RTV } 12 \text {-hourly to standard } \\
\text { dose of two tablets of LPV/r 12-hourly } \\
\text { There is an increased risk of hepatotoxicity with } \\
\text { these strategies } \\
\text { These dose adjustments can be made gradually over } \\
1 \text { - } 2 \text { weeks* }\end{array}$ \\
\hline & $\begin{array}{l}\text { All other } \\
\text { PIs }\end{array}$ & Marked reduction in PI concentrations & Do not prescribe concomitantly \\
\hline InSTI & RAL & $\begin{array}{l}\text { Reduction in concentrations, but a clinical trial showed that } \\
\text { standard dosing results in adequate virological suppression }\end{array}$ & $\begin{array}{l}\text { No dose adjustment required (i.e. RAL } 400 \mathrm{mg} \\
\text { 12-hourly) }\end{array}$ \\
\hline \multicolumn{4}{|c|}{$\begin{array}{l}\mathrm{ART}=\text { antiretroviral therapy; } \mathrm{RIF}=\text { rifampicin; } \mathrm{ARV}=\text { antiretroviral; } \mathrm{NRTI}=\text { nucleoside reverse transcriptase inhibitor; } \mathrm{NNRTI}=\text { non-nucleoside reverse transcriptase inhibitor; } \mathrm{EFV}=\text { efavirenz; } \\
\mathrm{NVP}=\text { nevirapine; } \mathrm{ETV}=\text { etravirine; } \mathrm{RPV}=\text { rilpivirine; } \mathrm{PI}=\text { protease inhibitor; } \mathrm{LPV}=\text { lopinavir; } \mathrm{LPV} / \mathrm{r}=\text { lopinavir/ritonavir; } \mathrm{RTV}=\text { ritonavir; InSTI = integrase inhibitor }(\text { integrase strand transfer } \\
\text { inhibitor); } \mathrm{RAL}=\text { raltegravir. }\end{array}$} \\
\hline
\end{tabular}

Table 7. Dosing of ARVs and RFB when prescribed concomitantly

\begin{tabular}{|c|c|c|}
\hline ARV dose & ARV change & RFB dosage \\
\hline EFV & None & Increase to $450 \mathrm{mg} /$ day \\
\hline NVP & None & $300 \mathrm{mg} /$ day \\
\hline ATV or RTV-boosted PIs & None & Decrease to $150 \mathrm{mg}$ every second day \\
\hline
\end{tabular}

Table 8. Shared side-effects of ART and TB treatment

\begin{tabular}{|c|c|c|}
\hline Side-effects & ART & TB treatment \\
\hline Nausea & AZT, ddI, PIs & Pyrazinamide, ethionamide \\
\hline Hepatitis & $\begin{array}{l}\text { NVP, EFV, PIs } \\
\text { (NRTIs can cause } \\
\text { steatohepatitis) }\end{array}$ & $\begin{array}{l}\text { RIF, INH, pyrazinamide and many } \\
\text { second-line drugs, including } \\
\text { quinolones }\end{array}$ \\
\hline Peripheral neuropathy & $\mathrm{d} 4 \mathrm{~T}, \mathrm{ddI}$ & $\begin{array}{l}\text { INH, ethionamide, terizidone/ } \\
\text { cycloserine }\end{array}$ \\
\hline Renal impairment & TDF & Aminoglycosides, RIF (rare) \\
\hline Rash & NVP, EFV, RAL & $\begin{array}{l}\text { RIF, INH, pyrazinamide, ethambutol, } \\
\text { streptomycin and many second-line } \\
\text { drugs, including quinolones }\end{array}$ \\
\hline $\begin{array}{l}\text { Neuropsychiatric } \\
\text { problems }\end{array}$ & $\mathrm{EFV}$ & $\begin{array}{l}\text { Terizidone/cycloserine, quinolones, } \\
\text { INH }\end{array}$ \\
\hline
\end{tabular}

robust than a PI in second-line therapy. Nevertheless, short-term use over 6 months is probably preferable to treating TB without
RIF, which has a high risk of failure or relapse. ART and TB medication share many side-effects (Table 8).

\subsection{Pregnancy}

AIDS is the most frequent cause of death in pregnant women in many southern African countries, ${ }^{[2]}$ and is a significant cause of morbidity and mortality in children born to HIV-positive women. Even where children are born HIV-negative to HIV-positive mothers, their mortality is significantly increased.

Traditionally, the focus on HIV and pregnancy has centred on the transmission of HIV to children. This has lead to complex regimens to address concerns about efficacy and resistance. These guidelines attempt, where possible, to simplify this approach, to decrease transmission in both pregnant and breastfeeding mothers, and facilitate the continuum of care.

\subsubsection{NNRTI and PI choice in pregnancy}

Based on the accumulated evidence, we endorse the WHO guidance that EFV can be used in pregnancy and in women who intend to fall pregnant. This is in contrast to our previous guidance. The FDA category D classification should be discussed with women, explaining that this was based on animal studies; human cohort studies have not demonstrated an increased risk of congenital abnormalities, but that there is a background low risk of congenital abnormalities 
in all pregnancies, unrelated to drugs.

EFV has been shown to be teratogenic in primates, resulting in craniofacial abnormalities in exposed offspring. There have been isolated human case reports of myelomeningocoele (neural tube defects) in infants following intrauterine exposure to EFV. The drug is classified by the US Food and Drug Administration (FDA) as a category D drug, meaning that 'there is positive evidence of human foetal risk, but the benefits from use in pregnant women may be acceptable despite the risk (e.g. if the drug is needed in a life-threatening situation or for a serious disease for which safer drugs cannot be used or are ineffective). It should be noted, however, that data supporting this classification are not supported by findings in cohorts of pregnant women exposed to EFV. In a meta-analysis, the incidence of neural tube defects and all congenital abnormalities among women exposed to EFV in the first trimester was similar to that of the general population. ${ }^{[53]}$ WHO guidance is that EFV can be used throughout pregnancy; their review of current data on EFV safety and risk of teratogenicity is reassuring and, from a public health perspective, the need for simplicity and the toxicity associated with NVP are considered to outweigh concerns regarding unproven risks associated with $\mathrm{EFV}{ }^{[54]}$

Studies have shown that total LPV concentrations are significantly reduced in pregnancy, but unbound LPV concentrations are not affected. ${ }^{[55]}$ Therefore, dose adjustment of $\mathrm{LPV} / \mathrm{r}$ is not recommended in pregnancy. However, once-daily dosing of LPV/r should not be used in pregnancy. Similarly, concentrations of boosted ATV are reduced in pregnancy, but trough concentrations are adequate and dose adjustments are not recommended in pregnancy. ${ }^{[5]}$ An exception is in patients who are also receiving TDF, as TDF may reduce ATV concentrations: ATV/r dose should be increased to $400 \mathrm{mg} / 100 \mathrm{mg}$ daily in such patients during the third trimester of pregnancy. Unboosted ATV is not recommended in pregnancy.

\subsubsection{General points}

Fertility choices in the context of HIV treatment are complex. Clinicians should check these choices at every patient visit to minimise risks. Adequate access to safe and effective contraception should be provided. For further guidance:

Southern African HIV Clinicians Society. Guideline on safer conception in fertile HIV-infected individuals and couples. S Afr J HIV Med 2011;12(2):31-44.

In particular:

- Clinicians should be aware that women may fall pregnant unintentionally, but that the response may still vary from welcoming the pregnancy to wanting a termination.

- In general, far too few women in the southern African region receive prophylaxis for PMTCT. Every effort must be made to ensure rapid ascertainment of HIV status and access to appropriate PMTCT with ART.

- SA data suggest that most HIV transmissions to babies occur from HIV-positive mothers with $\mathrm{CD} 4^{+}$counts $<350$ cells $/ \mu \mathrm{L}$. Rapid ART initiation for the mother at this level will have a large effect on both maternal and child health.

- All pregnant women of unknown HIV status or who were previously HIV-negative should be offered an HIV test, irrespective of previous sexual activity, marital status, social group or perceived HIV risk status. HIV testing should be repeated 3-monthly throughout pregnancy and breastfeeding. Some studies have suggested a greater
HIV acquisition risk during pregnancy.

- The study of MTCT is a rapidly evolving field, and international guidelines should be monitored for major changes.

\subsubsection{Recommendations}

For women who are HIV-infected and pregnant and not receiving ART, the following is recommended as the best standard of care in situations where resources are available:

- All HIV-infected pregnant women should be initiated on triple-drug ART, if adequately prepared, irrespective of $\mathrm{CD} 4^{+}$count and VL.

- $\mathrm{CD}^{+}$count testing and staging must be done quickly and ART adherence counselling should be accelerated, with the aim to initiate women on treatment within 2 weeks of the first visit (and more rapidly in the third trimester of pregnancy). Women who are being initiated onto ART for PMTCT should ideally be initiated after the first trimester, but women with a $\mathrm{CD} 4^{+}$count $<200$ cells $/ \mu \mathrm{L}$ or with severe HIV morbidity should be started in the first trimester.

- Women who elect to breastfeed should continue ART until weaning has occurred.

- Women with baseline $\mathrm{CD} 4^{+}$counts $<350$ cells $/ \mu \mathrm{L}$ should have their ART continued lifelong.

- In women with a $\mathrm{CD} 4{ }^{+}$count $>350$ cells/ $\mu \mathrm{L}$ after pregnancy and who have completed breastfeeding, lifelong ART should be discussed; if the patient is motivated, she should continue ART lifelong, otherwise stop safely and continue to have her $\mathrm{CD} 4^{+}$count monitored (section 13.1).

- If a woman presents during labour and is not receiving ART, singledose NVP should be given to mother and baby, with additional AZT and 3TC for 1 week, or single-dose TDF/FTC to the mother to reduce the risk of developing NNRTI resistance (NVP has a very long half-life). An alternative is to start triple-drug ART.

- Refer to PMTCT guidelines for recommended regimens for the baby.

\subsection{Renal failure}

\subsubsection{ARV dosages}

Renal function is estimated either by the modified Cockgraft-Gault equation (Table 9) or the modification of diet in renal disease (MDRD) method, which most laboratories report as eGFR. The results of these formulae differ slightly, but either can be used for clinical management. For peritoneal dialysis, the dose given with a $\mathrm{CrCl}<10 \mathrm{~mL} / \mathrm{min}$ should be given daily. For haemodialysis, the dose given with a $\mathrm{CrCl}<10 \mathrm{~mL} /$ min should be given daily, but must be given after dialysis on dialysis days, to prevent the drug from being dialysed out.

\subsubsection{ARV choice and dosing in patients on chronic haemodialysis}

Patients with HIV may develop end-stage renal failure requiring chronic haemodialysis owing to HIV-associated nephropathy or an HIV-unrelated cause. In patients on chronic haemodialysis, there are a number of important ART issues that arise. The NRTI class is eliminated through the kidneys, and thus doses of most NRTI drugs need to be adjusted in patients on dialysis (Table 9). Although TDF can be used in patients on chronic haemodialysis, dosing is once weekly, which can be difficult for patients to remember. AZT is generally avoided because of anaemia associated with chronic renal failure. Daily dosages or the evening doses of a twice-daily regimen of ARVs on the day of haemodialysis should be given after the haemodialysis session. NNRTI drugs do not require dose adjustment. 
Table 9. ARV dosage adjustments in renal failure*

\begin{tabular}{|c|c|c|c|c|}
\hline \multirow[b]{2}{*}{ Drug } & \multicolumn{2}{|c|}{$\mathrm{CrCl}(\mathrm{mL} / \mathrm{min})^{\ddagger \S}$} & \multirow{2}{*}{$\begin{array}{l}\text { Haemodialysis } \\
\text { (dose after dialysis) }\end{array}$} & \multirow{2}{*}{$\begin{array}{l}\text { Peritoneal } \\
\text { dialysis }\end{array}$} \\
\hline & $10-50$ & $<10$ & & \\
\hline TDF & AVOID & AVOID & $300 \mathrm{mg}$ once weekly & Unknown \\
\hline $\mathrm{ABC}$ & Unchanged & Unchanged & Unchanged & Unchanged \\
\hline $3 \mathrm{TC}$ & 150 mg daily & $50 \mathrm{mg}$ daily $^{\dagger}$ & $\begin{array}{l}50 \mathrm{mg} \text { first dose and } \\
\text { thereafter } 25 \mathrm{mg} \\
\text { daily }^{\dagger}\end{array}$ & $\begin{array}{l}50 \mathrm{mg} \text { first } \\
\text { dose and } \\
\text { thereafter } \\
25 \mathrm{mg} \text { daily }^{\dagger}\end{array}$ \\
\hline $\mathrm{AZT}$ & Unchanged & 300 mg daily & 300 mg daily & 300 mg daily \\
\hline $\mathrm{d} 4 \mathrm{~T}$ & $\begin{array}{l}15 \mathrm{mg} \\
\text { 12-hourly }\end{array}$ & 15 mg daily & 15 mg daily & Unknown \\
\hline ddI & $\begin{array}{l}>60 \mathrm{~kg} \text { body } \\
\text { weight: } \\
200 \mathrm{mg} \text { daily } \\
<60 \mathrm{~kg} \text { body } \\
\text { weight: } \\
150 \mathrm{mg} \text { daily }\end{array}$ & $\begin{array}{l}>60 \mathrm{~kg} \text { body } \\
\text { weight: } \\
125 \mathrm{mg} \text { daily } \\
<60 \mathrm{~kg} \text { body } \\
\text { weight: } \\
75 \mathrm{mg} \text { daily }\end{array}$ & $\begin{array}{l}>60 \text { kg body weight: } \\
125 \mathrm{mg} \text { daily } \\
<60 \mathrm{~kg} \text { body weight: } \\
75 \mathrm{mg} \text { daily }\end{array}$ & $\begin{array}{l}>60 \mathrm{~kg} \text { body } \\
\text { weight: } \\
125 \mathrm{mg} \text { daily } \\
<60 \mathrm{~kg} \text { body } \\
\text { weight: } \\
75 \mathrm{mg} \text { daily }\end{array}$ \\
\hline NNRTIs & Unchanged & Unchanged & Unchanged & Unchanged \\
\hline PIs & Unchanged & Unchanged & Unchanged & Unchanged \\
\hline InSTIs & Unchanged & Unchanged & Unchanged & Unchanged \\
\hline \multicolumn{5}{|c|}{$\begin{array}{l}\mathrm{ARV}=\text { antiretroviral; } \mathrm{CrCl}=\text { creatinine clearance; } \mathrm{TDF}=\text { tenofovir; } \mathrm{ABC}=\text { abacavir; } 3 \mathrm{TC}=\text { lamivudine; } \mathrm{AZT}=\text { zidovudine; } \\
\mathrm{d} 4 \mathrm{~T} \text { = stavudine; } \mathrm{ddI}=\text { didanosine; NNRTIs = non-nucleoside reverse transcriptase inhibitors; PIs = protease inhibitors; } \\
\text { InSTIs = integrase strand transfer inhibitors; eGFR = estimated glomerular filtration rate; NRTIs = nucleoside reverse transcriptase inhibitors. }\end{array}$} \\
\hline \multicolumn{5}{|c|}{$\begin{array}{l}\text { *This table was developed using: }(i) \text { Bartlett JG. Medical care of patients with HIV Infection 2010; (ii) The Sanford Guide to Antimicrobial } \\
\text { Therapy 2012; and (iii) HIV Medicine Association of the Infectious Diseases Society of America. Clinical Practice Guideline for the } \\
\text { Management of Chronic Kidney Disease in Patients Infected With HIV: } 2014 \text { Update. Clin Infect Dis 2014;59(9):e96-el38. }\end{array}$} \\
\hline \multicolumn{5}{|c|}{$\begin{array}{l}\text { Some experts recommend that the lowest available tablet dose of } 150 \mathrm{mg} 3 \mathrm{TC} \text { daily be used in patients with advanced renal disease } \\
\text { (creatinine clearance }<10 \mathrm{~mL} / \mathrm{min} \text { ) and patients on dialysis so as to avoid having to use the liquid formulation of 3TC, and because } \\
\text { of the favourable safety profile and lack of data to suggest } 3 \mathrm{TC} \text { dose-related toxicity.*(ii) } \\
\text { formulation is unavailable or not tolerated. }\end{array}$} \\
\hline \multicolumn{5}{|c|}{$\begin{array}{l}\text { *The modified Cockgraft-Gault equation: } \\
\text { Creatinine clearance }(\mathrm{CrCl})^{* *}=(140-\text { age } \times \text { ideal weight }) \div \text { serum creatinine } \\
\star * \text { For women, multiply the total by } 0.85 \text {. }\end{array}$} \\
\hline \multicolumn{5}{|c|}{$\begin{array}{l}\text { 'Many laboratories report the eGFR calculated using a variation of the modification of diet in renal disease (MDRD) formula. This } \\
\text { result can be used (in place of the calculated creatinine clearance) to make decisions regarding the use of TDF and for modification } \\
\text { of the dose of other NRTIs based on this table. }\end{array}$} \\
\hline
\end{tabular}

We recommend the following first-line option for patients on chronic haemodialysis:

- ABC $600 \mathrm{mg}$ daily

- 3TC $50 \mathrm{mg}$ first dose and thereafter $25 \mathrm{mg}$ daily (on the days when haemodialysis is performed, the dose should be given after the haemodialysis session)

- EFV 600 mg nocte.

ATV concentrations are reduced in patients on haemodialysis to a greater degree than LPV, and thus ATV is preferably not used in treatment-experienced patients. LPV/r should be used with twice daily dosing in patients on haemodialysis. We recommend an LPV/r-based second-line regimen with the NRTIs in the regimen selected after genotype resistance testing and consideration of issues related to NRTIs in patients on dialysis as discussed above. DRV/r and RAL may be used at standard dosages. It is suggested that patients on chronic haemodialysis (who generally receive ongoing medical care in a dialysis unit) are reviewed by a clinician experienced in ARV management at least 6-monthly, to monitor treatment efficacy and side-effects, and to adjust the regimen when needed.

\subsubsection{ARVs in patients with acute kidney injury (AKI)}

In patients with AKI, dosages of NRTI drugs should be adjusted based on estimated $\mathrm{CrCl}$ calculation (Table 9). TDF should be interrupted even if it is not thought to be the cause of the AKI. Once there is clear evidence that renal function is improving (creatinine on downward trend), NRTI dosages should be readjusted to standard dosages to avoid underdosing. In patients with AKI who are not yet receiving ART, initiation is preferably deferred until AKI has resolved.

\subsection{ARV dosages in liver impairment}

Unlike in renal impairment, there is no blood test that can accurately quantify liver impairment. Child-Pugh class $\mathrm{C}$ may require dose adjustment for the relevant ARVs listed in Table 10. In general, the combination of TDF with 3TC (or FTC) and RAL (or EFV, which can be hepatotoxic) is regarded as the least hepatotoxic. If the patient has active hepatitis $\mathrm{B}$, discontinuation of ARVs that have activity against hepatitis B (TDF, 3TC and FTC) can cause severe flares of hepatitis.

\subsection{Hepatitis B co-infection}

Hepatitis B is a common co-infection with HIV in southern Africa, with significant implications for progression to cirrhosis, as well as for treatment options. Clinicians are encouraged to support current efforts in the region to vaccinate all children for hepatitis B, and to extend coverage to eligible adults. Access to vaccination, laboratory resources and treatment options is limited to some extent in southern African countries, and the recommendations below should each be considered in the light of the local context.

All HIV-positive patients should be screened for active hepatitis B (limiting screening to those with liver function abnormalities will miss many cases, as liver enzymes are often normal in hepatitis B infection). HBsAg is an appropriate screening test. Hepatitis B VL correlates with disease progression and may be used to monitor antihepatitis B therapy, but it is expensive and availability is limited.

Hepatitis $\mathrm{B} / \mathrm{HIV}$ co-infection is associated with:

- an increased risk of chronic liver disease

- a higher hepatitis B VL

- diminished responses to hepatitis B vaccine

- poorer responses to interferon-alpha treatment

- an increased incidence of drug-induced hepatotoxicity (particularly with NVP)

- a flare of hepatitis within 3 months of commencing ART (due to hepatitis B-IRIS, which is difficult to differentiate from drug hepatotoxicity)

Drugs directed against hepatitis B that have no/ minimal antiHIV activity (e.g. entecavir and telbivudine) are largely unavailable or extremely expensive in our region. For practical purposes, the only available therapy is to use ARVs that also have antihepatitis B activity (TDF + 3TC/FTC). As with HIV, these drugs suppress hepatitis B, but do not eradicate it. Effective treatment prevents or slows progression to cirrhosis.

All patients who are HIV-infected and HBsAgpositive are eligible for ART irrespective of $\mathrm{CD} 4{ }^{+}$count. The ART regimen should include 
Table 10. Prescribing ARVs in liver impairment

\begin{tabular}{|c|c|c|}
\hline Class & Drug & Prescribing notes \\
\hline \multirow[t]{7}{*}{ NRTIs } & TDF & In patients with chronic hepatitis $\mathrm{B}$, there is a risk of rebound hepatitis when TDF is discontinued \\
\hline & FTC & $\begin{array}{l}\text { In patients with chronic hepatitis B, there is a risk of rebound hepatitis when FTC is discontinued or } \\
\text { if hepatitis B resistance to FTC develops }\end{array}$ \\
\hline & 3TC & $\begin{array}{l}\text { In patients with chronic hepatitis } \mathrm{B} \text {, there is a risk of rebound hepatitis when } 3 \mathrm{TC} \text { is discontinued or } \\
\text { if hepatitis B resistance to } 3 \mathrm{TC} \text { develops }\end{array}$ \\
\hline & AZT & Decrease dose by $50 \%$ or double dosage interval if significant liver disease \\
\hline & $\mathrm{ABC}$ & $\begin{array}{l}\text { Reduce adult dose to } 200 \mathrm{mg} \text { bd for significant liver impairment. Contraindicated in severe hepatic } \\
\text { impairment }\end{array}$ \\
\hline & $\mathrm{d} 4 \mathrm{~T}$ & Use with caution and never combine $\mathrm{d} 4 \mathrm{~T}$ and ddI in patients with liver disease \\
\hline & ddI & $\begin{array}{l}\text { Use with caution: reports implicate use as a risk factor for the development of hepatic } \\
\text { decompensation in patients being treated for cirrhosis due to hepatitis C }\end{array}$ \\
\hline \multirow[t]{4}{*}{ NNRTIs } & EFV & $\begin{array}{l}\text { Caution should be exercised in administering EFV to patients with liver disease; therapeutic drug } \\
\text { monitoring should be done if available }\end{array}$ \\
\hline & NVP & Avoid if significant hepatic impairment or active hepatitis B or C \\
\hline & ETV & $\begin{array}{l}\text { Use with caution in severe liver disease (Child-Pugh Class C) as dosage recommendation has not } \\
\text { been established }\end{array}$ \\
\hline & RPV & $\begin{array}{l}\text { Use with caution in severe liver disease (Child-Pugh Class C) as dosage recommendation has not } \\
\text { been established }\end{array}$ \\
\hline \multirow[t]{5}{*}{ PIs } & ATV & Avoid in severe hepatic impairment \\
\hline & $\mathrm{LPV} / \mathrm{r}$ & $\begin{array}{l}\text { LPV is highly metabolised in the liver and concentrations may be increased in patients with hepatic } \\
\text { impairment; therapeutic drug monitoring should be done if available }\end{array}$ \\
\hline & DRV & Use with caution or avoid if significant liver disease \\
\hline & IDV & Reduce unboosted adult dose to $600 \mathrm{mg}$ 8-hourly if significant hepatic impairment \\
\hline & SQV & $\begin{array}{l}\text { Avoid: there have been reports of worsening liver disease and development of portal hypertension } \\
\text { after starting SQV in patients with severe liver disease }\end{array}$ \\
\hline InSTI & RAL & No dosage adjustment necessary in mild-to-moderate hepatic insufficiency \\
\hline CCR5 blocker & MVC & Concentrations likely to be increased with hepatic impairment \\
\hline
\end{tabular}

TDF and 3TC (or FTC). Using 3TC without including TDF leads to hepatitis B resistance in $80-90 \%$ of patients after 5 years of treatment. If a patient meets the criteria for switching to a second-line ART regimen (to treat HIV), this combination (TDF + 3TC/FTC) should be continued to suppress hepatitis B infection, as interruption of TDF and/ or FTC/3TC has been associated with flares of life-threatening hepatitis. The second-line ART regimen should be shaped around these two drugs in consultation with an experienced HIV clinician. NVP should be avoided in patients with hepatitis B co-infection.

In patients with hepatitis $\mathrm{B}$ and renal dysfunction, the use of TDF may be considered with dosing frequency adjustment based on $\mathrm{CrCl}$ (see package insert) and more frequent creatinine monitoring. If renal dysfunction is severe or renal function deteriorates with TDF, then 3TC monotherapy (with or without pegylated interferon-alpha, which is very costly) should be considered.

\subsection{Malaria}

There are several drug interactions between antimalarials and ARVs:

Artemether-lumefantrine (Coartem) can safely be administered with NVP. EFV significantly lowers the concentrations of artemether (and its active metabolite) and lumefantrine, which is likely to increase the risk of failure of therapy. There is no clear guideline on how to overcome this interaction, but some experts recommend repeating the 3-day course of Coartem (i.e. treat for 6 days). Boosted PIs dramatically increase the plasma concentrations of lumefantrine, but a dose reduction is not recommended, as the toxicity threshold of lumefantrine seems to be high. Close monitoring for toxicity is recommended when coadministering artemether-lumefantrine with ART.

Quinine concentrations are significantly decreased by $\mathrm{LPV} / \mathrm{r}$, probably owing to induction of metabolism by RTV. It is likely that quinine concentrations will also be reduced by EFV and NVP; therefore, quinine should be avoided in patients receiving PIs or NNRTIs. Patients with severe malaria should receive artesunate, if this is available, and those with milder malaria should be treated with artemether-lumefantrine.

Among drugs used for chemoprophylaxis, there are no clinically significant pharmacokinetic interactions between ARVs and mefloquine or doxycycline. However, mefloquine and EFV both cause frequent neuropsychiatric side-effects; therefore, doxycycline is the preferred chemoprophylactic agent for patients receiving EFV.

There are several interactions with atovaquone-proguanil (Malanil). Atovaquone concentrations are reduced by PIs and EFV. It is also 
likely that NVP decreases atovaquone concentrations. Proguanil concentrations are also reduced by PIs and EFV. Use of atovaquoneproguanil is therefore best avoided in patients receiving PIs or NNRTIs.

\section{ARV toxicity monitoring and management}

Currently recommended ART is generally well tolerated. Many adverse drug reactions are mild and occur only in the first few weeks of therapy. If toxicity does not resolve or is severe, then the offending drug should be substituted as indicated below. It is important to ensure that the VL is suppressed before substituting a single drug for toxicity, otherwise resistance may develop to the new drug, consequently compromising future regimens. However, single-drug substitutions can be done in the first few months of ART without measuring the VL, as the VL may take up to 6 months to suppress.

It is rarely necessary to stop the entire ART regimen due to toxicity. It is advised to switch only the culprit drug and continue the rest of the ART regimen. In certain life-threatening situations (e.g. hepatitis with liver failure or lactic acidosis), it may be necessary to cease use of all ARVs.

\subsection{Haematological toxicity}

Cytopenias occur commonly in HIV infection without exposure to ART. Patients receiving AZT, d4T or CTX may experience abnormalities in their FBCs. Significant bone marrow toxicity from CTX generally only occurs with high doses used for treating OIs. Patients receiving prophylactic CTX rarely develop isolated neutropenia. FBC monitoring is necessary with AZT; this should be performed monthly for 3 months, then after 6 months of therapy and thereafter if clinically indicated (it is unusual to see haematological toxicity occurring after 6 months). The main problem arising from AZT use is anaemia and neutropenia; platelet counts generally rise with use of the drug. Management guidelines are provided in Table 11. Macrocytosis is usual with $\mathrm{d} 4 \mathrm{~T}$ and AZT therapy; there is no need to measure vitamin B12 and folate concentrations unless there are other indications that these may be deficient.

Pure red cell aplasia, which presents with severe anaemia and low reticulocyte production index, has rarely been associated with 3TC. A bone marrow examination should be performed to confirm the condition. Parvovirus B19 infection should be excluded (a polymerase chain reaction (PCR) test should be requested on blood sent in an ethylenediaminetetra-acetic acid (EDTA) tube).

\subsection{Hepatotoxicity}

- Liver function tests (LFTs) should be performed at ART initiation and the measurement intervals should be tailored thereafter to individual drug regimens. The full panel of LFTs is expensive; therefore, it is recommended that only ALT is monitored, as this is the most sensitive indicator of drug-induced liver injury (DILI). The full LFT profile should be requested in patients with symptoms suggestive of hepatitis. All ARV classes have been associated with hepatotoxicity - most commonly NNRTIs. NRTIs very rarely present with acute hepatitis. Mild ALT elevations occur very commonly and usually transiently with many drugs in general. ALT elevations $>5 \times$ the upper limit of normal (ULN) are significant in the absence of symptoms. In the presence of symptoms of hepatitis, ALT elevations $>2.5 \times$ ULN are significant.

- Ideally, in patients starting NVP, ALT should be monitored at 2, 4, 8 and 12 weeks after initiation. If monitoring is performed, a system should be in place to obtain the result and contact the patient; routine ALT monitoring makes little sense in settings where the result will only be available when the patient is seen in $2-4$ weeks, or where the patient cannot be contacted. It is essential to educate all patients starting NVP about the symptoms of hepatitis (nausea, vomiting, anorexia, malaise, jaundice and right-upper-quadrant pain) and drug rash, which is frequently associated with hepatitis. Hepatitis often follows the rash after about 10 days. If such symptoms develop, ALT should be determined urgently.

- Hepatotoxic drugs should be discontinued at high levels of LFT abnormality (Table 12) or at lower levels if any symptoms of hepatitis appear and an alternative ARV agent substituted. Rechallenge may be considered in selected cases; a specialist should be consulted. If hepatitis occurs together with a rash or fever, or with other systemic involvement, then rechallenge with NNRTIs, ABC or CTX should not be attempted.

- Prolonged use of NRTIs, especially d4T and ddI, may cause fatty liver. Typically, ALT concentration is more significantly elevated than AST, and the concentrations of canalicular enzymes (gammaglutamyl transferase (GGT) and alkaline phosphatase (ALP)) are more elevated than those of the transaminases. Non-tender hepatomegaly may be present. Ultrasound or computed tomography (CT) imaging may show decreased hepatic density. The condition is not benign and fibrosis has been reported with long-term ddI use. Patients should be advised to avoid alcohol. Patients receiving $\mathrm{d} 4 \mathrm{~T}$ or ddI should be switched to safer NRTIs.

- In patients with severe hepatitis or jaundice, the international normalised ratio (INR) and serum glucose should be assessed, as well as features of hepatic encephalopathy (i.e. features of hepatic failure).

- If the concentration of canalicular enzymes is more significantly elevated than that of ALT, or if conjugated bilirubin is elevated, an ultrasound of the liver should be conducted to exclude biliary obstruction.

- Isolated unconjugated hyperbilirubinaemia (drug-induced Gilbert's syndrome) is associated with certain PIs (IDV and especially ATV). In this case, all other LFTs are normal and the patient has no other symptoms of hepatitis. Although this is a benign condition (it does not reflect liver injury, but isolated competitive inhibition of the enzyme in the liver which conjugates bilirubin), it is often cosmetically unacceptable to patients.

- Patients with underlying hepatitis B or C infection may experience a flare of hepatitis when ART is commenced, as a consequence of IRIS. Hepatitis B can also flare when ARVs that have activity against it (TDF, 3TC and FTC) are discontinued or when hepatitis B resistance develops.

- Many other drugs can cause hepatotoxicity, notably antiTB agents (including prophylactic isoniazid) and azoles. CTX is an uncommon cause of hepatitis, often as part of a systemic hypersensitivity reaction.

- Recommendations for the management of DILI in patients receiving TB treatment have been published by the Society in 2013:

- Jong E, Conradie F, Berhanu R, et al. Consensus statement: Management of drug-induced liver injury in HIV-positive patients treated for TB. S Afr J HIV Med 2013;14(3):113-119.

\subsection{Hyperlactataemia}

This side-effect has become less common with fewer patients starting ART with d4T and with the use of lower doses of d4T. It can also occur occasionally with AZT, but clinicians should be aware that this side-effect can occur with all other NRTIs, although it is very rare with ABC, TDF, 
Table 11. Guidelines for managing haematological toxicity (mainly AZT-induced)

\begin{tabular}{|c|c|c|c|c|}
\hline $\mathrm{Hb}(\mathrm{g} / \mathrm{dL})$ & $\begin{array}{l}>8: \\
\text { Monitor }\end{array}$ & $\begin{array}{l}7.0 \text { - 7.9: } \\
\text { Repeat } 4 \text { weeks } \\
\text { Reduce AZT } 200 \mathrm{mg} \text { bd } \\
\text { or consider switching } \\
\text { from AZT }\end{array}$ & $\begin{array}{l}6.5-6.9 \text { : } \\
\text { Repeat } 2 \text { weeks } \\
\text { Consider switching } \\
\text { from AZT }\end{array}$ & $\begin{array}{l}<6.5 \text { : } \\
\text { Switch from } \\
\text { AZT }\end{array}$ \\
\hline $\begin{array}{l}\text { Neutrophils } \\
\left(\times 10^{9} / \mathrm{L}\right)\end{array}$ & $\begin{array}{l}1.0-1.5: \\
\text { Repeat } \\
4 \text { weeks }\end{array}$ & $\begin{array}{l}0.75 \text { - } 0.99: \\
\text { Repeat } 2 \text { weeks }\end{array}$ & $\begin{array}{l}0.50-0.74 \text { : } \\
\text { Repeat } 2 \text { weeks } \\
\text { Consider switching } \\
\text { from AZT }\end{array}$ & $\begin{array}{l}<0.5 \\
\text { Switch from } \\
\text { AZT }\end{array}$ \\
\hline
\end{tabular}

Table 12. Guidelines for managing hepatotoxicity

\begin{tabular}{|c|c|c|c|}
\hline \multirow[b]{2}{*}{$\mathrm{ULN}^{*}$} & \multicolumn{3}{|c|}{ Elevation } \\
\hline & $<2.5 \times \mathrm{ULN}$ & $2.5-5 \times \mathrm{ULN}$ & $>5 \times \mathrm{ULN}$ \\
\hline ALT & Monitor & Repeat at 1 week & $\begin{array}{l}\text { Discontinue relevant } \\
\operatorname{drug}(\mathrm{s})\end{array}$ \\
\hline ALP & Monitor & Repeat at 2 weeks & $\begin{array}{l}\text { Ultrasound; consider } \\
\text { biopsy }\end{array}$ \\
\hline Bilirubin & $\begin{array}{l}\text { Repeat at } \\
1 \text { week }\end{array}$ & $\begin{array}{l}\text { Discontinue relevant } \\
\operatorname{drug}(\mathrm{s})\end{array}$ & $\begin{array}{l}\text { Discontinue relevant } \\
\operatorname{drug}(\mathrm{s})\end{array}$ \\
\hline
\end{tabular}

3TC and FTC. Mildly elevated lactate is not uncommon in patients treated with NRTIs, but is generally asymptomatic. Asymptomatic elevated lactate does not predict the development of lactic acidosis; it is therefore unnecessary to monitor levels in asymptomatic patients.

- Lactic acidosis is a serious, rare, potentially fatal side-effect of NRTIs, most commonly associated with $\mathrm{d} 4 \mathrm{~T}$, particularly when combined with ddI. Symptomatic hyperlactataemia without acidosis is more common, but seldom seen with the safer NRTIs that are currently recommended.

- The combination of $\mathrm{d} 4 \mathrm{~T}$ and $\mathrm{ddI}$ is associated with a high risk of symptomatic hyperlactactaemia or lactic acidosis, particularly in pregnancy. This combination should therefore be avoided.

- Symptoms are nonspecific and include nausea and vomiting, abdominal pain, dyspnoea, fatigue and weight loss.

- Risk factors for hyperlactataemia include:

- female gender

- obesity

- the use of NRTIs for $>6$ months

- the development of NRTI-induced peripheral neuropathy or fatty liver.

- A raised lactate of $>5 \mathrm{mmol} / \mathrm{L}$ together with metabolic acidosis confirms the diagnosis of lactic acidosis. Low serum bicarbonate $(<20 \mathrm{mmol} / \mathrm{L})$ is the most sensitive marker of acidosis. Associated abnormalities include elevated AST and ALT, lactate dehydrogenase and creatinine kinase. Treatment is supportive.

The management of symptomatic hyperlactataemia depends on lactate and bicarbonate concentrations:

- Lactate $<5 \mathrm{mmol} / \mathrm{L}$ and bicarbonate $>20 \mathrm{mmol} / \mathrm{L}$ : NRTIs should be switched to agents less frequently associated with hyperlactataemia: TDF/ABC + FTC/3TC. Symptoms and serial lactate should be monitored for several months (lactate levels decrease slowly over weeks).

- Lactate $>5 \mathrm{mmol} / \mathrm{L}$ and bicarbonate $>15$ mmol/L: Patient should be admitted and NRTIs should be discontinued. If the patient is on an NNRTI regimen, then a boosted PI should be added. If the patient has already failed an NNRTI and is on a boosted PI, then RAL and/or ETV should be added, if available, or the patient should be continued on the boosted PI only. When lactate has normalised, the patient should be switched to TDF/ABC + 3TC/FTC, as above.

- Lactate $>5 \mathrm{mmol} / \mathrm{L}$ and bicarbonate $<15 \mathrm{mmol} / \mathrm{L}$ : The patient should be admitted, preferably to an ICU, and NRTIs should be discontinued. If the patient is on an NNRTI regimen, a boosted PI should be added. If the patient has already failed an NNRTI regimen and is receiving a boosted PI, then RAL and/or ETV should be added, if available, or the patient should be continued on a boosted PI only. Bicarbonate replacement is controversial, but most experts would use this strategy to partially correct severe acidosis. Broad-spectrum antibiotics are recommended as sepsis can mimic NRTI-induced lactic acidosis (this can be discontinued if procalcitonin is normal). On recovery, all NRTIs should be avoided in future regimens, although some experts would recommend a trial of safer NRTIs with lactate monitoring, as above.

For further guidance:

Southern African HIV Clinicians Society. Guidelines for the prevention, diagnosis and management of NRTI-hyperlactataemia and lactic acidosis. S Afr J HIV Med 2006;7(1):8-15.

The potential of NRTIs to cause elevated lactate varies (from most likely to least likely): d4T/ddI > AZT > TDF/FTC/3TC/ABC

\subsection{Dyslipidaemia}

- PIs, with the exception of unboosted ATV, can cause fasting hypertriglyceridaemia and elevated low-density lipoprotein (LDL) cholesterol. Boosted ATV is associated with less severe dyslipidaemia; $\mathrm{d} 4 \mathrm{~T}$ can cause mild hypertriglyceridaemia, and EFV can cause elevated total cholesterol and mild hypertriglyceridaemia.

- Diet and lifestyle modification should always be advised. Diet is more effective for controlling hypertriglyceridaemia than hypercholesterolaemia. Other cardiovascular risk factors should be addressed.

- If patients receiving PIs develop dyslipidaemia that warrants lipid-lowering therapy, then they should be switched to boosted ATV, if possible, rather than adding therapy for the dyslipidaemia. Switching the PI to RAL is another option, because RAL has a favourable lipid profile. However, RAL should only be used in a regimen with two other ARVs known to be fully active.

- Marked hypertriglyceridaemia (>10 $\mathrm{mmol} / \mathrm{L})$ can cause pancreatitis and requires urgent treatment with diet, fibrates and switching to boosted ATV (fibrates can be stopped after 1 month, followed by reassessment). Indications for statin therapy 
in HIV-positive patients should be the same as in HIV-negative patients, according to the Framingham heart disease risk score. Many statins have interactions with PIs that can lead to potentially toxic statin concentrations, with the exception of pravastatin and fluvastatin. Atorvastatin concentrations are significantly raised by PIs, but low doses (e.g. $10 \mathrm{mg}$ daily) can be used with monitoring for symptoms of myalgia. Lovastatin and simvastatin should not be coadministered with PIs, as their concentrations are dramatically increased and severe rhabdomyolysis has been reported.

- We suggest assessing lipids after 3 months on a PI regimen. If normal at this stage, reassessment should be performed only in those with other cardiovascular risk factors.

\subsection{Lipodystrophy}

- Long-term ART use may cause changes in body fat distribution (lipodystrophy). This can present with fat accumulation (visceral obesity, breast enlargement, 'buffalo hump' or lipomata) or subcutaneous fat loss (lipoatrophy, most noticeable in the face, limbs and buttocks), or with both forms of lipodystrophy.

- The thymidine analogue NRTIs (AZT and especially $\mathrm{d} 4 \mathrm{~T}$ ) are associated with fat loss.

- Lipoatrophy improves when d4T/AZT are substituted with TDF or $\mathrm{ABC}$, but resolution is very slow and often incomplete; therefore, it is important to recognise lipoatrophy early or, better still, to use NRTIs that are not associated with the condition.

- Previously, PIs were thought to be the cause of lipohypertrophy. However, more recent studies have shown that all classes of ARVs are associated with fat gain to the same extent. Furthermore, longitudinal studies comparing HIV-negative people with HIV-positive people on long-term ART have demonstrated that the extent and distribution of fat gain are similar. A systematic review of RCTs concerning switching ARVs for fat accumulation failed to show any benefit. ${ }^{[57]}$ These data indicate that fat gain is a consequence of treating HIV rather than a drug-specific side-effect. Telling the patient that the ARVs are causing fat gain is not only incorrect, but may result in the patient discontinuing ART. The appearance of the fat gain is particularly unsightly when accompanied by subcutaneous fat loss.

- There is no good evidence to support the switching of ARVs in patients with fat accumulation. Healthy diet and exercise should be advocated, as in the HIV-negative population. Surgery should be considered in selected cases with focal fat gain (e.g. those with prominent 'buffalo humps'). Metformin modestly reduces weight and improves insulin resistance in patients with the metabolic syndrome or isolated dysglycaemia.

- Visceral fat accumulation is associated with insulin resistance and dyslipidaemia. Other cardiovascular risk factors should be addressed in all patients.

\subsection{Hypersensitivity}

- Rash with NNRTIs is common (more severe and frequent with NVP) in the first 6 weeks of therapy. If the rash is accompanied by systemic features (e.g. fever, elevated ALT or hepatitis), mucosal involvement or blistering, then the NNRTI should be discontinued immediately and rechallenge must not be performed as these are features of lifethreatening reactions. If the rash is mild and occurs without these features, then the NNRTI can be continued and the rash can be treated symptomatically with antihistamines, and possibly topical steroids. Systemic steroids should not be used.
- In patients who develop mild rashes during the low-dose NVP lead-in phase (200 mg daily), the dosage must not be increased to $200 \mathrm{mg}$ 12-hourly until the reaction has resolved. This 'treatthrough' approach is only acceptable if the patient can be observed carefully, otherwise NVP should be substituted.

- There is a possible cross-reaction between NVP and EFV, although most studies report no evidence of this. It is acceptable to substitute EFV for NVP in the event of hypersensitivity, unless the reaction was severe. There are hardly any data on substituting NVP for EFV in the event of hypersensitivity; therefore, this substitution is not recommended.

- $\mathrm{ABC}$ hypersensitivity is primarily a systemic reaction occurring within the first 8 weeks of therapy in $\sim 3 \%$ of cases. Fatalities may occur on rechallenge. Therapy must be discontinued and never reintroduced. The manifestations of hypersensitivity include fever, rash, fatigue and abdominal or respiratory symptoms. If there is any doubt concerning the diagnosis (e.g. if the patient has a cough with fever), then the patient should be admitted for observation. Symptoms progress if hypersensitivity is present. The hypersensitivity reaction has been shown to occur on a genetic basis, being confined to people with the HLA-B ${ }^{\star} 5701$ allele, which is very uncommon in Africans. It is thus less frequent in patients of African descent. If testing is affordable and available, this allele should be excluded prior to using ABC.

- Other ARVs, notably RAL and DRV, can occasionally cause hypersensitivity rashes, including life-threatening rashes.

- CTX is a common cause of cutaneous and systemic hypersensitivity reactions, indistinguishable from hypersensitivity reactions to ARVs. CTX should be interrupted when treating mild suspected NNRTI cutaneous hypersensitivity rashes, and permanently discontinued if severe hypersensitivity reactions occur.

\subsection{Nephrotoxicity}

Analysis for serum creatinine and urine proteinuria must be performed at baseline in all patients to detect subclinical renal disease, as there is an increased risk of renal failure in HIV infection due to a variety of causes. The dose of NRTIs needs to be adjusted in renal failure (Table 9). In a minority of patients, TDF may cause a tubular wasting syndrome (including wasting of phosphate and potassium). If patients receiving TDF develop muscle weakness or other muscle symptoms, then potassium and phosphate levels must be assessed. TDF can also cause acute renal failure, but this is uncommon. TDF should be discontinued immediately in patients with acute renal failure and should generally never be restarted (switch to ABC or another NRTI). Consider recommencing with careful monitoring when the renal failure has resolved only if an alternative cause of renal failure is established and TDF was considered not to have contributed.

We recommend that it is essential to estimate the $\mathrm{CrCl}$ before commencing TDF, which should not be used if the eGFR or $\mathrm{CrCl}$ is $<50 \mathrm{~mL} / \mathrm{min}$. For patients receiving TDF, creatinine should be monitored at 3 months, 6 months and then 6-monthly thereafter. In high-risk patients (particularly those with coexistent hypertension or diabetes), creatinine should also be checked at 1 and 2 months. Long-term use of TDF with other nephrotoxic agents (e.g. aminoglycosides or non-steroidal antiinflammatory agents (NSAIDs)) should be avoided. Where TDF is avoided because $\mathrm{CrCl}$ is $<50 \mathrm{~mL} / \mathrm{min}$ at baseline, it may be possible to switch to TDF at a later point if renal function improves. This is often the case where patients had diarrhoea or other OIs at the time of ART initiation. 


\subsection{Neuropsychiatric toxicity}

AZT and RAL frequently cause headaches when started, but this usually resolves. EFV frequently causes neuropsychiatric effects in the first few weeks of therapy, typically presenting with insomnia, vivid dreams and dizziness. Both dysphoria and euphoria may occur. Fortunately, these features subside in the majority of patients within the first $4-6$ weeks. Psychosis may occasionally occur. If the neuropsychiatric effects of EFV are not tolerated, then the patient should be switched to RPV, NVP (if the $\mathrm{CD} 4^{+}$count is $<250$ cells $/ \mu \mathrm{L}$ in women or $<400$ cells $/ \mu \mathrm{L}$ in men; if virologically suppressed, then EFV can be switched to NVP at higher $\mathrm{CD} 44^{+}$counts as this is not associated with increased risk of rash-associated hepatitis), lower dose EFV (400 mg daily) or RAL. Patients starting EFV should be warned about these symptoms, and reassured that they resolve in most patients continuing the drug, but if not, that an alternative can be substituted.

\subsection{Dysglycaemia}

The older PIs, notably IDV, may cause diabetes. However, the newer PIs (ATV, DRV and LPV) do not. EFV, AZT and d4T are associated with small increased risks of dysglycaemia. Visceral fat gain, which occurs to a similar extent with all ARV classes, is associated with insulin resistance. Blood glucose should be assessed serially in these patients as part of a cardiovascular risk assessment.

\subsection{Gynaecomastia}

Gynaecomastia involves the development of breast tissue in men. This is not related to lipodystrophy. It may be bilateral or unilateral. Serum testosterone should be measured and replacement therapy given if this is low. Gynaecomastia is most consistently associated with EFV, so suppressed patients should be switched to RPV or NVP.

\section{IRIS}

Approximately $10-20 \%$ of patients who start ART with advanced immunosuppression experience clinical deterioration during the first months due to IRIS. Two forms are recognised:

- Unmasking IRIS occurs in patients who have an unrecognised OI when ART is initiated, and who then present with exaggerated inflammatory features of that infection during early ART due to it being 'unmasked' by recovering immunity.

- Paradoxical IRIS occurs in patients who are being treated for an OI when they start ART, but who develop an immune-mediated worsening or recurrence of features of that infection after starting ART.

IRIS is most frequently described in association with TB and CM. Skin conditions such as molluscum contagiosum and Kaposi's sarcoma may also worsen due to IRIS. The diagnosis of IRIS can be difficult, mainly because there is no confirmatory diagnostic test. Diagnosis relies on recognition of the characteristic clinical presentation, ensuring that OIs are correctly diagnosed, and excluding alternative causes for deterioration, such as drug resistance (e.g. MDR-TB). Case definitions for TB and cryptococcal IRIS have been published. ${ }^{[58,59]}$ It is important to ensure that the underlying OI is treated appropriately. ART should be continued, unless IRIS is life-threatening (e.g. neurological involvement in TB-IRIS with depressed level of consciousness). Corticosteroids have been shown to reduce morbidity and improve symptoms in paradoxical TB-IRIS, ${ }^{[60]}$ and can be used in mycobacterial and fungal forms of IRIS when other causes for deterioration have been excluded, and particularly when IRIS features are severe. For paradoxical TB-IRIS, prednisone can be commenced at a dose of $1.5 \mathrm{mg} / \mathrm{kg} /$ day and weaned over 4 weeks, but a longer course may be required if symptoms recur on weaning. Steroids should not be used in patients with Kaposi's sarcoma. Practical guidance for TB-IRIS management has been published. ${ }^{[61]}$

\section{Support and counselling}

The patient should be informed about the benefits of ART and that side-effects are usually minor and transient, or manageable. The patient should be given a treatment plan, specifying the reasons for commencing therapy and the drugs to be used (with names and details including the appearance of each drug, when and how they are to be taken, and a brief indication of anticipated side-effects and toxicity).

Adherence in the order of $\geq 90 \%$ is required for virological suppression. Poor adherence results in the development of drug resistance. There is a bell-shaped relationship between adherence and resistance: patients with very poor resistance may not acquire resistance because of insufficient drug pressure to select for resistance. The patient should be encouraged to discuss drug-related issues with his/her clinician.

\section{Prophylaxis in patients receiving ART \\ $20.1 \mathrm{Ols}$}

The use of appropriate prophylaxis (primary or secondary) is essential in patients initiating ART. In general, prophylaxis can be discontinued once the $\mathrm{CD}^{+}$count has increased to 200 cells/ $\mu \mathrm{L}$ (but certain minimal durations of prophylaxis apply for secondary prophylaxis - local and international guidelines should be consulted).

\subsection{Isoniazid preventive therapy (IPT)}

A recent clinical trial conducted in SA showed that IPT has an additive effect with ART in preventing incident TB in HIV-positive patients. ${ }^{[62]}$ There was a $37 \%$ reduction in incident $\mathrm{TB}$ when patients receiving ART were prescribed IPT (v. placebo) for 12 months. This benefit applied irrespective of tuberculin skin test (TST) status, and the trial included patients established on ART. All patients receiving ART should be considered for IPT and screened for active TB using a symptom screen ${ }^{[63]}$ - defer IPT and investigate for active TB if any of the four symptoms (current cough, fever, night sweats or weight loss) are present. Consider sputum TB culture in all patients with a $\mathrm{CD} 4^{+}$count $<200$ cells $/ \mu \mathrm{L}$ before IPT initiation where feasible. In patients receiving IPT, monitor for neuropathy and hepatitis symptoms. Routine ALT monitoring is not indicated. The duration of IPT depends on TST and ART status as outlined in Table 13.

Funding and support. This work is supported and funded by the Southern African HIV Clinicians Society.

Table 13. Indications for and duration of IPT

\begin{tabular}{lll}
\hline TST & Pre-ART & On ART \\
\hline Not done & IPT for 6 months & IPT for 12 months \\
Negative & IPT not indicated & IPT for 12 months \\
Positive & IPT for at least 36 months & IPT for at least 36 months \\
IPT = isoniazid preventive therapy; TST = tuberculin skin test; ART = antiretroviral therapy.
\end{tabular}


Conflicts of interest. All expert panel members have completed and submitted conflict of interest disclosure forms. Disclosure information represents the previous 3 years (updated 1 December 2014) and includes relationships with pharmaceutical companies and medical aids. F Conradie has received support from Abbvie, Aspen and Mylan to attend conferences; research support from Janssen; honoraria for speaking engagements from Abbvie, Janssen and MSD; and acted as a consultant to Sanofi Aventis. T Manzini has received support from Mylan and Cipla to attend conferences. M Mathe has received support from Janssen to attend conferences and honoraria from Janssen for speaking engagements. G Meintjes has received honoraria for speaking engagements from Sanofi Aventis and serves as a consultant for Aid for AIDS. M Moorhouse has received honoraria for speaking engagements from Aspen and MSD. Y Moosa has received honoraria for speaking at conferences from Abbvie, MSD and Mylan, and acted as a consultant for Mylan and Pfizer. C Orrell has received support to attend conferences from Tibotec and honoraria from Abbott for a speaking engagement. Y Pakade has received support from Aspen to attend a conference. F Venter has received honoraria for speaking engagements from MSD, Novogen, Aspen and Adcock-Ingram; has served on advisory boards for Abbott, Pfizer, Johnson and Johnson, Mylan and Tibotec; and has received study drug for investigator-led studies from Gilead. J Black, V Cox, S Dlamini, J Fabian, G Maartens, C Menezes, J Nash and D Wilson report no conflicts of interest.

\section{References}

1. Johnson LF, Mossong J, Dorrington RE, et al. International Epidemiologic Databases to Evaluate AIDS Southern Africa Collaboration. Life expectancies of South African adults starting antiretroviral treatment: Collaborative analysis of cohort studies. PLoS Med 2013;10(4):e1001418. [http://dx.doi.org/0.1371/journal.pmed.1001418]

2. Severe P, Juste MA, Ambroise A, et al. Early v. standard antiretroviral therapy for HIV-infected adults in Haiti. N Engl J Med 2010;363(3):257265. [http://dx.doi.org/10.1056/NEJMoa0910370]

3. Writing Committee for the CASCADE Collaboration. Timing of HAART initiation and clinical outcomes in human immunodeficiency virus type 1 seroconverters. Arch Intern Med 2011;171(17):1560-1569. [http://dx.doi. org/10.1001/archinternmed.2011.401]

4. Cain LE, Logan R, Robins JM, et al. When to initiate combined antiretroviral therapy to reduce mortality and AIDS-defining illness in HIV-infected persons in developed countries: An observational study. Ann Intern Med 2011;154(8):509-515. [http://dx.doi.org/10.7326/0003-4819154-8-201104190-00001]

5. Kitahata MM, Gange SJ, Abraham AG, et al. Effect of early v. deferred antiretroviral therapy for HIV on survival. N Engl J Med 2009;360(18):18151826. [http://dx.doi.org.10.1056/NEJMoa0807252]

6. Sterne JA, May M, Costagliola D, et al. Timing of initiation of antiretroviral therapy in AIDS-free HIV-1-infected patients: A collaborative analysis of 18 HIV cohort studies. Lancet 2009;373(9672):1352-1363. [http://dx.doi. org/10.1016/S0140-6736(09)60612-7]

7. Cohen MS, Chen YQ, McCauley M, et al. Prevention of HIV-1 infection with early antiretroviral therapy. N Engl J Med 2011;365(6):493-505. [http://dx.doi.org/0.1056/NEJMoa1105243]

8. Tanser F, Bärnighausen T, Grapsa E, Zaidi J, Newell ML. High coverage of ART associated with decline in risk of HIV acquisition in rural KwaZuluNatal, South Africa. Science 2013;339(6122):966-971. [http://dx.doi. org/10.1126/science.1228160]

9. Petersen ML, Wang Y, van der Laan MJ, Rhee SY, Shafer RW, Fessel WJ. Virologic efficacy of boosted double versus boosted single protease inhibitor therapy. Aids 2007;21(12):1547-1554. [http://dx.doi.org/10.1097/ QAD.0b013e32825a69a8]

10. Badri M, Ehrlich R, Wood R, Pulerwitz T, Maartens G. Association between tuberculosis and HIV disease progression in a high tuberculosis prevalence area. Int J Tuberc Lung Dis 2001;5(3):225-232.

11. Abdool Karim SS, Naidoo K, Grobler A, et al. Integration of antiretroviral therapy with tuberculosis treatment. N Engl J Med 2011 365(16):1492-
1501. [http://dx.doi.org/10.1056/NEJMoa1014181]

12. Blanc FX, Sok T, Laureillard D, et al. Earlier v, later start of antiretroviral therapy in HIV-infected adults with tuberculosis. $\mathrm{N}$ Engl J Med 2011;365(16):1471-1481. [http://dx.doi.org/10.1056/NEJMoa1013911]

13. Havlir DV, Kendall MA, Ive P, et al. Timing of antiretroviral therapy for HIV-1 infection and tuberculosis. N Engl J Med 2011;365(16):1482-1491. [http://dx.doi.org/10.1056/NEJMoa1013607]

14. Mfinanga SG, Kirenga BJ, Chanda DM, et al. Early v. delayed initiation of highly active antiretroviral therapy for HIV-positive adults with newly diagnosed pulmonary tuberculosis (TB-HAART): A prospective, international, randomised, placebo-controlled trial. Lancet Infect Dis 2014;14(7):563-571. [http://dx.doi.org/10.1016/S1473-3099(14)70733-9]

15. Török ME, Yen NT, Chau TT, et al. Timing of initiation of antiretroviral therapy in human immunodeficiency virus (HIV)-associated tuberculous meningitis. Clin Infect Dis 2011;52(11):1374-1383. [http://dx.doi.org/10.1093/cid/cir230]

16. Zolopa A, Andersen J, Powderly W, et al. Early antiretroviral therapy reduces AIDS progression/death in individuals with acute opportunistic infections: A multicenter randomized strategy trial. PLoS One 2009;4(5):e5575. [http://dx.doi.org/10.1371/journal.pone.0005575]

17. Boulware DR, Meya DB, Muzoora C, et al. Timing of antiretroviral therapy after diagnosis of cryptococcal meningitis. N Engl J Med 2014;370(26):2487-2498. [http://dx.doi.org/10.1056/NEJMoa1312884]

18. Saez-Cirion A, Bacchus C, Hocqueloux L, et al. Post-treatment HIV-1 controllers with a long-term virological remission after the interruption of early initiated antiretroviral therapy ANRS VISCONTI Study. PLoS Pathogens 2013;9(3):e1003211. [http://dx.doi.org/10.1371/journal.ppat.1003211]

19. Riddler SA, Haubrich R, DiRienzo AG, et al. Class-sparing regimens for initial treatment of HIV-1 infection. N Engl J Med 2008;358(20):20952106. [http://dx.doi.org/10.1056/NEJMoa074609]

20. Cohen CJ, Molina JM, Cassetti I, et al. Week 96 efficacy and safety of rilpivirine in treatment-naive, HIV-1 patients in two Phase III randomized trials. Aids 2013;27(6):939-950. [http://dx.doi.org/10.1097/ QAD.0b013e32835cee6e]

21. Molina JM, Clumeck N, Orkin C, et al. Week 96 analysis of rilpivirine or efavirenz in HIV-1-infected patients with baseline viral load $</=100000$ copies $/ \mathrm{mL}$ in the pooled ECHO and THRIVE phase 3, randomized, doubleblind trials. HIV Med 2014;15(1):57-62. [http://dx.doi.org/10.1111/hiv.12071]

22. ENCORE1 Study Group, Puls R, Amin J, et al. Efficacy of $400 \mathrm{mg}$ efavirenz v. standard $600 \mathrm{mg}$ dose in HIV-infected, antiretroviral-naive adults (ENCORE1): A randomised, double-blind, placebo-controlled, non-inferiority trial. Lancet 2014;383(9927):1474-1482. [http://dx.doi. org/10.1016/S0140-6736(13)62187-X]

23. Post FA, Moyle GJ, Stellbrink HJ, et al. Randomized comparison of renal effects, efficacy, and safety with once-daily abacavir/lamivudine v. tenofovir/emtricitabine, administered with efavirenz, in antiretroviralnaive, HIV-1-infected adults: 48-week results from the ASSERT study. J Acquir Immune Defic Syndr 2010;55(1):49-57. [http://dx.doi.org/10.1097/ QAI.0b013e3181dd911e]

24. Sax PE, Tierney C, Collier AC, et al. Abacavir-lamivudine v. tenofoviremtricitabine for initial HIV-1 therapy. N Engl J Med 2009;361(23):22302240. [http://dx.doi.org/10.1056/NEJMoa0906768]

25. Cruciani M, Mengoli C, Malena M, et al. Virological efficacy of abacavir: Systematic review and meta-analysis. J Antimicrob Chemother 2014;69(12):3169-3180. [http://dx.doi.org/10.1093/jac/dku279]

26. Ribaudo HJ, Benson CA, Zheng Y, et al. No risk of myocardial infarction associated with initial antiretroviral treatment containing abacavir: Short and long-term results from ACTG A5001/ALLRT. Clin Infect Dis 2011;52(7):929-940. [http://dx.doi.org/10.1093/cid/ciq244]

27. Sabin CA, Worm SW, Weber R, et al. Use of nucleoside reverse transcriptase inhibitors and risk of myocardial infarction in HIV-infected patients enrolled in the D:A:D study: A multi-cohort collaboration. Lancet 2008;371(9622):14171426. [http://dx.doi.org/10.1016/S0140-6736(08)60423-7]

28. Cruciani M, Zanichelli V, Serpelloni G, et al. Abacavir use and cardiovascular disease events: A meta-analysis of published and unpublished data. AIDS 2011;25(16):1993-2004. [http://dx.doi. org/10.1097/QAD.0b013e328349c6ee]

29. Ford N, Meintjes G, Pozniak A, et al. The future role of CD4 cell count for monitoring antiretroviral therapy. Lancet Infect Dis. Published online 19 Nov 2014. [http://dx.doi.org/10.1016/S1473-3099(14)70896-5]

30. Rawizza HE, Chaplin B, Meloni ST, et al. Immunologic criteria are poor predictors of virologic outcome: Implications for HIV treatment monitoring in resource-limited settings. Clin Infect Dis 2011;53(12):12831290. [http://dx.doi.org/10.1093/cid/cir729]

31. Manasa J, Katzenstein D, Cassol S, Newell ML, de Oliveira T. Primary drug resistance in South Africa: Data from 10 years of surveys. AIDS Res Hum Retroviruses 2012;28(6):558-565. [http://dx.doi.org/10.1089/ aid.2011.0284]

32. Smith CJ, Sabin CA, Lampe FC, et al. The potential for CD4 cell increases in HIV-positive individuals who control viraemia with highly active antiretroviral therapy. AIDS 2003;17(7):963-969. [http://dx.doi. org/10.1097/01.aids.0000060352.78202.79]

33. Guihot A, Tubiana R, Breton G, et al. Immune and virological benefits of 10 
years of permanent viral control with antiretroviral therapy. AIDS 2010;24(4):614617. [http://dx.doi.org/10.1097/QAD.0b013e32833556f3]

34. Kaufmann GR, Furrer H, Ledergerber B, et al. Characteristics, determinants, and clinical relevance of $\mathrm{CD} 4 \mathrm{~T}$ cell recovery to $<500$ cells $/ \mu \mathrm{L}$ in HIV type 1 -infected individuals receiving potent antiretroviral therapy. Clin Infect Dis 2005;41(3):361 372. [http://dx.doi.org/10.1086/431484]

35. Mocroft A, Phillips AN, Gatell J, et al. Normalisation of CD4 counts in patients with HIV-1 infection and maximum virological suppression who are taking combination antiretroviral therapy: An observational cohort study. Lance 2007;370(9585):407-413. [http://dx.doi.org/ 10.1016/S0140-6736(07)609489/10.1016/S0140-6736(07)60948-9]

36. Loutfy MR, Genebat M, Moore D, et al. A CD4 $4^{+}$cell count $<200$ cells per cubic millimeter at 2 years after initiation of combination antiretroviral therapy is associated with increased mortality in HIV-infected individuals with vira suppression. J Acquir Immune Defic Syndr 2010;55(4):451-459.

37. Tuboi SH, Pacheco AG, Harrison LH, et al. Mortality associated with discordant responses to antiretroviral therapy in resource-constrained settings. J Acquir Immune Defic Syndr 2010;53(1):70-77. [http://dx.doi.org/10.1097/ QAI.0b013e3181c22d19]

38. Ledergerber B, Lundgren JD, Walker AS, et al. Predictors of trend in CD4-positive T-cell count and mortality among HIV-1-infected individuals with virological failure to all three antiretroviral-drug classes. Lancet 2004;364(9428):51-62. [http:// dx.doi.org/10.1016/S0140-6736(04)16589-6]

39. Paton NI, Kityo C, Hoppe A, et al. Assessment of second-line antiretrovira regimens for HIV therapy in Africa. N Engl J Med 2014;371(3):234-247. [http:// dx.doi.org/10.1056/NEJMoa1311274]

40. Johnson M, Grinsztejn B, Rodriguez C, et al. 96-week comparison of once-daily atazanavir/ritonavir and twice-daily lopinavir/ritonavir in patients with multiple virologic failures. AIDS 2006;20(5):711-718. [http://dx.doi.org/10.1097/01 aids.0000216371.76689.63]

41. Molina JM, Andrade-Villanueva J, Echevarria J, et al. Once-daily atazanavir/ritonavi compared with twice-daily lopinavir/ritonavir, each in combination with tenofovi and emtricitabine, for management of antiretroviral-naive HIV-1-infected patients: 96-week efficacy and safety results of the CASTLE study. J Acquir Immune Defic Syndr 2010;53(3):323-332. [http://dx.doi.org/10.1097/QAI.0b013e3181c990bf]

42. Hamers R, Sigaloff K, Wallis C, et al.; and PharmAccess African Studies to Evaluate Resistance (PASER). Patterns of HIV-1 Drug-Resistance after First-line ART Failure and Response to Second-line ART in a Multi-country Cohort: Sub-Saharan Africa. 19th Conference on Retroviruses and Opportunistic Infections. Seattle, 5-8 March 2012. Abstract 104.

43. Yazdanpanah Y, Fagard C, Descamps D, et al. High rate of virologic suppression with raltegravir plus etravirine and darunavir/ritonavir among treatment-experienced patients infected with multidrug-resistant HIV: Results of the ANRS 139 TRIO trial. Clin Infect Dis 2009;49(9):1441-1449. [http://dx.doi.org/10.1086/630210]

44. Arastéh K, Yeni P, Pozniak A, et al. Efficacy and safety of darunavir/ritonavir in treatment-experienced HIV type-1 patients in the POWER 1,2 and 3 trials at week 96. Antivir Ther 2009;14(6):859-864. [http://dx.doi.org/10.3851/1301]

45. Steigbigel RT, Cooper DA, Teppler $\mathrm{H}$, et al. Long-term efficacy and safety of raltegravir combined with optimized background therapy in treatmentexperienced patients with drug-resistant HIV infection: Week 96 results of the BENCHMRK 1 and 2 Phase III trials. Clin Infect Dis 2010;50(4):605-612. [http:// dx.doi.org/10.1086/650002]

46. Lazzarin A, Campbell T, Clotet B, et al. Efficacy and safety of TMC125 (etravirine) in treatment-experienced HIV-1-infected patients in DUET-2: 24-week results from randomised, double-blind, placebo-controlled trial. Lancet 2007;370(9581):39-48 [http://dx.doi.org/10.1016/S0140-6736(07)61048-4]

47. Madruga JV, Cahn P, Grinsztejn B, et al. Efficacy and safety of TMC125 (etravirine) in treatment-experienced HIV-1-infected patients in DUET-1: 24-week results from a randomised, double-blind, placebo-controlled trial. Lancet 2007;370(9581):2938. [http://dx.doi.org/10.1016/S0140-6736(07)61047-2]

48. Stevens WS, Wallis CL, Sanne I, Venter F. Will etravirine work in patients failing non-nucleoside reverse transcriptase inhibitor-based treatment in southern Africa? J Acquir Immune Defic Syndr 2009;52(5):655-656. [http://dx.doi.org/10.1097/ QAI.0b013e3181balb00]

49. El-Sadr WM, Lundgren J, Neaton JD, et al.; Strategies for Management of Antiretroviral Therapy (SMART) Study Group. CD4 ${ }^{+}$count-guided interruption of antiretroviral treatment. N Engl J Med 2006;355(22):2283-2296. [http://dx.doi. org/10.1056/NEJMoa062360]

50. Wainberg MA, Zaharatos GJ, Brenner BG. Development of antiretroviral drug resistance N Engl J Med 2011;365(7):637-646. [http://dx.doi.org/10.1056/NEJMra1004180]

51. Davies G, Cerri S, Richeldi L. Rifabutin for treating pulmonary tuberculosis. Cochrane Database Syst Rev 2007;(4):CD005159. [http://dx.doi.
[ org/10.1002/14651858.CD005159.pub2]

52. Bradshaw D, Chopra M, Kerber K, et al. Every death counts: Use of mortalit audit data for decision making to save the lives of mothers, babies, and children in South Africa. Lancet 2008;371(9620):1294-1304. [http://dx.doi.org/10.1016/S01406736(08)60564-4]

53. Ford N, Calmy A, Mofenson L. Safety of efavirenz in the first trimester of pregnancy: An updated systematic review and meta-analysis. AIDS 2011;25(18):2301-2304 [http://dx.doi.org/10.1097/QAD.0b013e32834cdb71]

54. World Health Organization. Technical update on treatment optimization. Use of efavirenz during pregnancy: A public health perspective. Geneva: World Health Organization, 2012.
55. Patterson KB, Dumond JB, Prince HA, et al. Protein binding of lopinavir and ritonavir during 4 phases of pregnancy: Implications for treatment guidelines. J Acquir Immune Defic Syndr 2013;63(1):51-58. [http://dx.doi.org/10.1097/ QAI.0b013e31827fd47e]

56. Eley T, Bertz R, Hardy H, Burger D. Atazanavir pharmacokinetics, efficacy and safety in pregnancy: A systematic review. Antivir Ther 2013;18(3):361-375. [http:// dx.doi.org/10.3851/IMP2473]

57. De Waal R, Cohen K, Maartens G. Systematic review of antiretroviral-associated lipodystrophy: lipoatrophy, but not central fat gain, is an antiretroviral adverse drug reaction. PLoS One 2013;8(5):e63623. [http://dx.doi.org/10.1371/journal. pone.0063623]

58. Haddow LJ, Colebunders R, Meintjes G, et al. Cryptococcal immune reconstitution inflammatory syndrome in HIV-1-infected individuals: Proposed clinical case definitions. Lancet Infect Dis 2010;10(11):791-802. [http://dx.doi.org/10.1016/ S1473-3099(10)70170-5]

59. Meintjes G, Lawn SD, Scano F, et al. Tuberculosis-associated immune reconstitution inflammatory syndrome: Case definitions for use in resourcelimited settings. Lancet Infect Dis 2008;8(8):516-523. [http://dx.doi.org/10.1016/ S1473-3099(08)70184-1]

60. Meintjes G, Wilkinson RJ, Morroni C, et al. Randomized placebo-controlled trial of prednisone for paradoxical tuberculosis-associated immune reconstitution inflammatory syndrome. Aids 2010;24(15):2381-2390. [http://dx.doi.org/10.1097/ QAD.0b013e32833dfc68]

61. Meintjes G, Sonderup MW. A practical approach to the diagnosis and management of paradoxical tuberculosis immune reconstitution inflammatory syndrome. Continuing Medical Education 2011;29(10):410-417.

62. Rangaka MX, Wilkinson RJ, Boulle A, et al. Isoniazid plus antiretroviral therapy to prevent tuberculosis: A randomised double-blind, placebo-controlled trial. Lancet 2014;384(9944):682-690. [http://dx.doi.org/10.1016/S01406736(14)60162-8]

63. Getahun H, Kittikraisak W, Heilig CM, et al. Development of a standardized screening rule for tuberculosis in people living with HIV in resourceconstrained settings: Individual participant data meta-analysis of observational studies. PLoS Med 2011;8(1):e1000391. [http://dx.doi.org/10.1371/journal. pmed.1000391]

\section{Supplementary material S1. Starting ART in hospital}

Starting ART in eligible patients in an inpatient setting can be considered in certain circumstances, and should strongly be considered during prolonged hospitalisation, where adherence, toxicity management and other support can be directly provided. However, limited data have shown what many experienced clinicians predicted: that patients who are initiated on ART within hospital have high default rates. This may be due to several factors: patients who wait to become severely ill and enter hospital may still have high levels of denial; they may be too ill to take in adherence counselling; and discharge may not be managed well. The clinician must carefully weigh up the high risk of deferring ART in terms of mortality and morbidity, and the risk for the individual patient of default, which cannot be predicted easily.

If a patient is considered for initiation in hospital, the following should be attended to:

\section{S1.1 In hospital}

- Before discharge, the patient must understand the reasons for ART initiation.

- If the patient is too ill or not mentally competent, then a caregiver and/or family member who will act as a directly observed therapy supporter should be involved.

- Care should be exercised regarding ART drug interactions with concomitant medication.

\section{S1.2 On discharge}

- Give very clear ART clinic directions, with a referral letter and details of documentation needed by the clinic.

- Patients should be encouraged to attend the ART clinic as soon as possible for an appointment and should be informed of reasonable clinic appointment waiting times.

- Sufficient medication must be provided to last until the ART clinic 
visit.

- These patients are often discharged on newly initiated TB treatment; few programmes as yet offer integrated TB/ART clinical services, and the need for separate clinical visits should be explained carefully.

- Discharging patients directly into the care of adequately counselled family members can be invaluable.

\section{S2. High-risk patients}

Patients who are at high risk for early mortality, IRIS and ART sideeffects include patients with:

- a low body mass index, anaemia and low albumin levels

- newly diagnosed OIs, especially TB and CM

- low $\mathrm{CD}^{+}$counts.

These patients should be initiated on ART as quickly as possible after any underlying OIs have been addressed (note the specific guidelines regarding ART timing in TB and CM in the guidelines), and should be counselled about the risk of IRIS, which may be misinterpreted as a sign of ART side-effects. Ideally, patients should have access to rapid referral systems, in the events of experiencing complicated IRIS or side-effects.

In addition, patients with any of the following are at high risk of default or inadequate adherence:

- uncontrolled depression

- poverty

- ambivalence about their HIV status

- distrust of the formal health sector

- lack of home support or high levels of community stigma

- alcohol or other substance abuse

- postpartum women.

Adherence issues are addressed in the Southern African Antiretroviral Resistance Treatment Guidelines, and include: attention to treating mental illness and substance use; giving access to support groups; addressing potential workplace-related issues including drug toxicity issues; additional counselling if denial is an issue; honest discussions about alternative health providers and churches that may undermine adherence; better postpartum integration of women/child HIV services; and actively linking poorer patients to poverty alleviation programmes.

\section{S3. Common ART misconceptions}

- You cannot take ART if you do not have food available. None of the commonly used first- and second-line options have meaningful food restrictions (although RPV should be taken with food). Patients should be warned that their appetite may return and that this may even be uncomfortable. However, food insecurity should be managed actively through rapid referral, and this should never be a reason to delay ART initiation.

- Doses need to be taken at precisely the same time each day. This myth was especially prevalent in the earlier days of ART, with anecdotes of patients returning to clinic in despair, after having interrupted their therapy for several weeks after missing a dose due to oversleeping by an hour. Encouraging patients to establish a routine helps with adherence, but delayed dosing is rarely a problem, even if out by many hours. Most of the drugs have long half-lives, and patients should be told simply to take their dose once they remember to do so.

- You must never drink alcohol again. Heavy alcohol use may affect adherence, and may potentiate the hepatic toxicity of ART and other hepatic pathology. However, data do not support the commonly held notion that alcohol speeds up the progression to AIDS, nor is there any evidence that moderate alcohol use has any negative effect on the health of HIV-positive individuals. Local guidelines for the general population around responsible alcohol use should be followed; prohibition is not advocated.

- Disclosure is a prerequisite for ART. This myth probably followed early experiences with highly rationed ART, where all possible adherence strategies were aggressively pursued to optimise outcomes, and bringing in a 'treatment buddy' was required to access ART. However, it became a form of punishment by some unsophisticated counsellors and clinicians, often under the pretext of preventing transmission, through making HIV status public. This tactic is almost certainly illegal and is certainly unethical, and while disclosure may assist patients with support and adherence, this should be suggested and based on the patient's individual circumstances. Forced disclosure can result in violence at the hands of a partner or community, and undermines confidence in confidentiality within the entire health system. Patients should be counselled about the pros and cons of disclosure, and assisted through the process as needed.

- Unprotected sex causes virological failure. This myth probably emerges from a convoluted understanding of the transmission of resistant virus. Theoretically, unprotected sex with someone who is failing ART may allow for the passage of resistant virus, but this is unusual. Patients should be counselled about safe sex; however, unprotected sex itself will not result in virological failure.

\section{S4. Practical measures for monitoring and enhancing adherence and retention in care}

The success of an individual's ART hinges on how well the tablets are taken. At least 90\%, preferably more, of treatment doses need to be taken as prescribed and gaps in therapy avoided in order to prevent the development of resistance. Most people will need support in maintaining high levels of treatment adherence. The areas below reflect adherence measures that are evidence based and should be in place for all those receiving ART.

\section{S4.1 Causes of poor adherence}

These are often complex and linked to social issues. Common causes include:

- Inadequate treatment literacy. Most HIV programmes have extraordinary adherence rates compared with other chronic diseases; this is largely due to efforts to ensure that patients understand HIV. If a patient fails therapy, some examination of the preART counselling may be merited.

- Side-effects. Side-effects are a very common reason for patients to default therapy. A careful history of often subtle but distressing side-effects (bad dreams, sleepiness, poor concentration, nausea, loss of appetite, change of body shape), in conjunction with a work history (shift work in particular) may allow for drug substitutions. Subtle lipoatrophy changes from $\mathrm{d} 4 \mathrm{~T}$ and AZT are often not taken seriously by healthcare providers, until disfiguring. Regular enquiry and immediate drug substitutions where possible should form part of every healthcare worker encounter.

- Depression and other mental illnesses. Undiagnosed or undertreated 
depression and other mental illness (the frequency of major depression is twice as high in HIV-positive subjects than in matched HIV-negative subjects) may undermine adherence. Patients with depression usually respond well to an antidepressant medication in combination with non-pharmaceutical interventions. If they do respond, then the medication should be given for at least 6 months.

- Poverty and food insecurity. Both of these have been related to poor adherence and increased missed clinic visits. Patients often lose their jobs due to ill health during the period leading up to ART initiation, and should be encouraged to return to the job market as soon as feasible or to seek support. This may lead to moving away from the ART clinic, and referral must be facilitated. Access to available grants, social support and employment non-governmental organisations (NGOs) may provide additional support.

- Work-related issues. These include shift work and the ability to visit clinics on weekdays. They are a major cause of poor adherence. Long clinic waiting times, including monthly pick-ups, may render maintaining employment untenable, especially with an unsympathetic employer. Clinicians should try to encourage clinics to be flexible, run smoothly for healthy patients, and provide 3 - 6-monthly pharmacy refills.

- Substance use. Excessive alcohol use may cause significant problems with adherence. In addition, other recreational drugs may cause problems in certain parts of the country, and use fluctuates according to availability and fad.

- Social problems. These include stigma and poor social support networks. Perceived stigma is correlated with poor adherence; this may manifest in a fear of tablets being found, an inability to solicit family or partner support, or anxiety regarding an employer, neighbours or a community. Social support groups may assist.

\section{S4.2 Pretreatment preparedness}

Anyone commencing ART needs to be prepared for treatment. This can be done on a one-toone basis or in a group session, by a trained doctor, nurse or counsellor. While treatment preparation involves imparting information on HIV and ART to the patient, sessions should also include identifying an individual's barriers to therapy (e.g. depression, alcohol use, nondisclosure or food security (Table S1)) and addressing any misconceptions about ART.

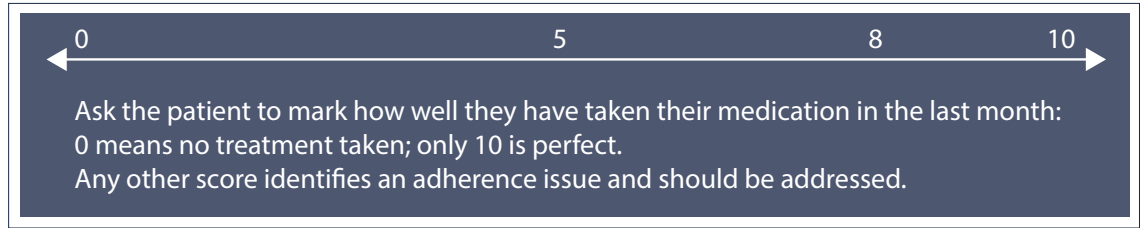

Fig. S1. An example of a visual analogue scale.



Fig. S2. Calculating pharmacy refill adherence.

\section{Table S1. Possible reasons for poor adherence}

\begin{tabular}{lll}
\hline Individual & Provider & Medication \\
\hline Depression & Stock-outs & High pill burden \\
Alcohol or substance use & Inaccessible clinics (both in & Frequent dosing (>once per day) \\
Non-disclosure & place and time) & Adverse effects \\
Adolescence & & \\
$\begin{array}{l}\text { Pregnancy } \\
\text { Food insecurity }\end{array}$ & &
\end{tabular}

The minimum information should include: - that ART is beneficial, but it is lifelong therapy

- the importance of excellent adherence to tablet-taking and to care

- side-effects of the current regimen, and a plan for what to do and who to contact if serious side-effects occur.

A flipchart to highlight key points in treatment preparedness session can be accessed at:

http://sahivsoc.org/topics?page $=1 \&$ curre ntFilter $=$ Adherence $\% 20$ and $\% 20$ HIV\%20 Drug\%20Resistance.

This information can be given over two to three sessions around the time of treatment commencement.

\section{S4.3 On-treatment monitoring}

Adherence must be monitored during therapy. Ideally both subjective and objective adherence should be assessed at every visit.
Two easy subjective measures include selfreport (asking the number of doses missed in the last 3 days or 1 week) or a visual analogue scale (Fig. S1). Subjective methods are not sensitive (most people do not admit to missing doses), but are specific (if a missed dose is noted, adherence issues are very likely and should be addressed). Pharmacy refill is a reliable method of assessing adherence. Most medications are refilled monthly and assessing how many months of medication are collected over a fixed period (6 or 12 months) is a sensible way of determining adherence (Fig. S2). Couriering medication unfortunately removes this method of assessment.

\section{S4.4 Using VL}

There is a growing body of evidence to show that resuppression of VL after an initial raised VL on treatment is possible in $56-68 \%$ of individuals. Any raised VL after $>3$ months on ART should be treated urgently and an adherence intervention must be implemented. 
This intervention would include exploration of adherence practices and further education on viral resistance and failure. Any issues from Table S1 that were not completely addressed should be identified, and disclosure to at least one other person who could act as a treatment supporter should actively be encouraged. A pillbox or other reminder system should be implemented, if not already in use. ART should be dispensed monthly, to allow more frequent contact with ART staff, until the $\mathrm{VL}$ is $<50$ copies $/ \mathrm{mL}$.

Ideally, a VL measurement should be repeated 2 - 3 months after commencing this adherence intervention.

\section{S4.5 Noticing if patients miss visits}

Each provider should have a system in place in order to notice when a patient misses a visit or does not collect their ARVs. Rapid follow-up within a few days of a missed visit with a phone call or a home visit by a counsellor may serve to prevent a gap in treatment.

\section{S4.6 Watching for high-risk groups}

Be aware that certain subsets of people are at higher risk of poor adherence and loss to follow-up. These include pregnant women, children and adolescents, and the mentally ill (including those who are depressed). These groups should be monitored more closely and managed actively.

This may include monthly attendance to see a counsellor for additional support and monitoring of adherence, or referral to specific support groups or services (e.g. Mothers to Mothers to Be, Alcoholics Anonymous, an adolescent-friendly clinic or psychological services), as appropriate.

\section{S4.7 Practical adherence tools}

Tools such as pillboxes, diaries and setting alarms may help patients to remember to take their medication. Having an emergency supply of a single dose on hand (e.g. in the handbag or workbag) may be useful for situations when patients have unexpected delays in getting home. Medicine formulations and trade names may change, and patients should be educated to recognise the generic name of their current regimen to avoid confusion.

Additional adherence and resistance educational resources from the Southern African HIV Clinicians Society are available at: http:// sahivsoc.org/topics? page $=1 \&$ currentFilter $=$ Adherence $\% 20$ and $\% 20$ HIV\%20Drug\%20Resistance

\section{References}

- Bärnighausen T, Chaiyachati K, Chimbindi N, Peoples A, Haberer J, Newell ML. Interventions to increase antiretroviral adherence in sub-Saharan Africa: A systematic review of evaluation studies. Lancet Infect Dis 2011;11(12):942-951. [http://dx.doi.org/10.1016/S1473-3099(11)70181-5]

- Thompson MA, Mugavero MJ, Amico KR, et al. Guidelines for improving entry into and retention in care and antiretroviral adherence for persons with HIV: Evidence-based recommendations from an International Association of Physicians in AIDS Care panel. Ann Intern Med 2012;156(11):817-833. [http://dx.doi. org/10.7326/0003-4819-156-11-201206050-00419]

- Bonner K1, Mezochow A, Roberts T, Ford N, Cohn J. Viral load monitoring as a tool to reinforce adherence: A systematic review. J Acquir Immune Defic Syndr 2013;64(1):74-78. [http://dx.doi.org/10.1097/QAI.0b013e31829f05ac]

\section{Appendix: WHO stage 3 and 4 conditions (2006 revision)}

\section{WHO stage 3 conditions}

- Unexplained severe weight loss ( $>10 \%$ of presumed or measured body weight)

- Unexplained chronic diarrhoea persisting for longer than 1 month

- Unexplained persistent fever (intermittent or constant for longer than 1 month)

- Persistent oral candidiasis

- Oral hairy leukoplakia

- Pulmonary TB (current)

- Severe bacterial infections (e.g. pneumonia, empyema, pyomyositis, bone or joint infection, meningitis, bacteraemia, severe pelvic inflammatory disease)

- Acute necrotising ulcerative stomatitis, gingivitis or periodontitis

- Unexplained anaemia $(<8 \mathrm{~g} / \mathrm{dL})$, neutropenia $\left(<0.5 \times 10^{9} / \mathrm{L}\right)$ and/ or chronic thrombocytopenia $\left(<50 \times 10^{9} / \mathrm{L}\right)$.

\section{WHO stage 4 conditions}

- HIV wasting syndrome

- Pneumocystis pneumonia

- Recurrent severe bacterial pneumonia

- Chronic herpes simplex virus infection (orolabial, genital or anorectal of more than 1 month's duration, or visceral at any site)

- Oesophageal candidiasis (or candidiasis of trachea, bronchi or lungs)

- Extrapulmonary TB

- Kaposis sarcoma

- Cytomegalovirus infection (retinitis or infection of other organs)

- CNS toxoplasmosis

- HIV encephalopathy

- Extrapulmonary cryptococcosis including meningitis

- Disseminated non-tuberculous mycobacteria infection

- Progressive multifocal leukoencephalopathy

- Chronic cryptosporidiosis

- Chronic isosporiasis

- Disseminated mycosis (extrapulmonary histoplasmosis, coccidiomycosis)

- Recurrent septicaemia (including non-typhoidal salmonella)

- Lymphoma (cerebral or B-cell non-Hodgkin's)

- Invasive cervical carcinoma

- Atypical disseminated leishmaniasis

- Symptomatic HIV-associated nephropathy

- Symptomatic HIV-associated cardiomyopathy 